\title{
PREDICTION OF JAPANESE COLOR SCORE
}

by

\author{
SUZANNE MARIE RYAN
}

B.S., Kansas State University, 2004

\begin{abstract}
A THESIS
submitted in partial fulfillment of the requirements for the degree

MASTER OF SCIENCE

Department of Animal Sciences and Industry

College of Agriculture

\section{KANSAS STATE UNIVERSITY \\ Manhattan, Kansas}

2007

Approved by:

Major Professor

John A. Unruh
\end{abstract}




\begin{abstract}
The objective of our study was to explore relationships between Japanese color score (JCS) and pork-quality attributes and develop equations to predict JCS. Pork carcass traits in population one $(n=781)$ was used to develop prediction equations and population two $(n=684)$ was used to test the equations for accuracy. Pearson's correlation coefficients found firmness, ultimate $\mathrm{pH}$, drip loss percentage, $\mathrm{L}^{*}, \mathrm{a}^{*}, \mathrm{~b}^{*}$, hue angle, and chroma were significantly $(P<0.01)$ correlated to JCS. Correlation loading found $96 \%$ of the variation in firmness, $\mathrm{pH}$, drip loss percentage, $\mathrm{L}^{*}, \mathrm{a}^{*}, \mathrm{~b}^{*}$, and hue angle explained $81 \%$ of the variation in JCS. Three prediction equations were developed using these traits. Averages for population one traits were used to develop the initial prediction equations. Predicted JCS, which fell within \pm 0.25 of the actual JCS, were retained and multiple linear regression (MLR) was run, resulting in the first prediction equations. Data from population two were then used to evaluate the success of these equations. Equation one using firmness, $\mathrm{pH}$, drip loss percentage, $\mathrm{L}^{*}, \mathrm{a}^{*}, \mathrm{~b}^{*}$, and hue angle was: JCS $=$ $12.698-(0.00007199 \times$ drip loss $)+(0.09008 \times \mathrm{pH})-(0.01128 \times$ firmness $)-(0.226 \times \mathrm{L} *)+$ $\left(0.06923 \times \mathrm{a}^{*}\right)-\left(0.0201 \times \mathrm{b}^{*}\right)+(0.02143 \times$ hue angle $) ; \mathrm{r}^{2}=0.916$. For the test population, 98.53 and $67.25 \%$ of the observations were predicted within \pm 0.50 and 0.25 of the actual JCS, respectively. The second prediction equation, developed utilizing instrumental color measures of $L^{*}, b^{*}$, and hue angle was: JCS $=15.255-\left(0.259 \times L^{*}\right)-\left(0.213 \times b^{*}\right)+(0.02518 \times$ hue angle $)$; $r^{2}=0.931$. For test population, 92.40 and $55.70 \%$ of the observations were predicted within \pm 0.50 and 0.25 of the actual JCS, respectively. The third prediction equation developed utilizing $L^{*}, a^{*}$, and $b^{*}$ was: JCS $=12.920-\left(0.219 \times L^{*}\right)+\left(0.07342 \times a^{*}\right)-\left(0.02166 \times b^{*}\right) ; r^{2}=0.906$. For test population, 97.80 and $68.22 \%$ of the observations were predicted within \pm 0.50 and 0.25 of the actual JCS, respectively. All prediction equations predicted $92 \%$ or more of the JCS observations within \pm 0.50 and would be useful when sorting pork carcasses for export to valuable Asian markets. The second and third prediction equations would be advantageous as they require fewer measurements and could be more rapidly collected.
\end{abstract}




\section{Table of Contents}

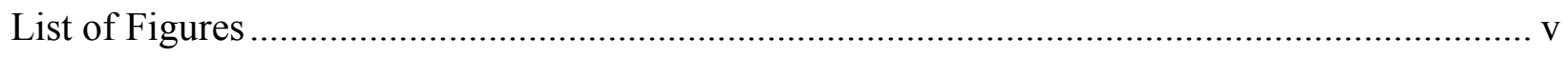

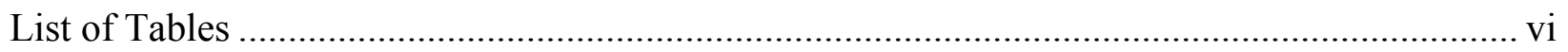

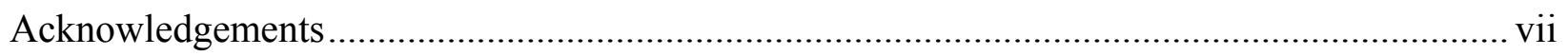

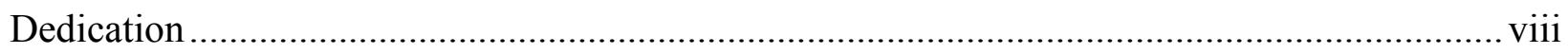

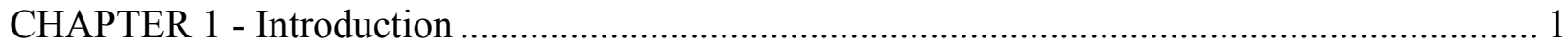

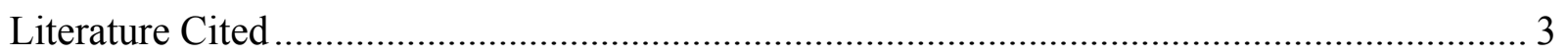

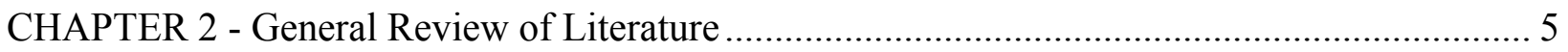

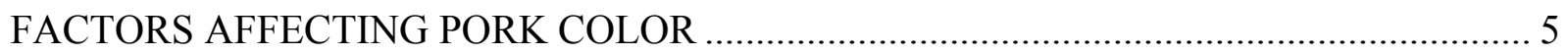

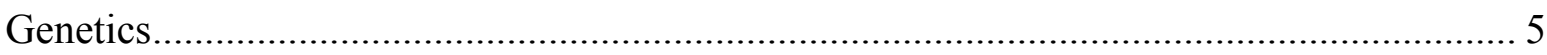

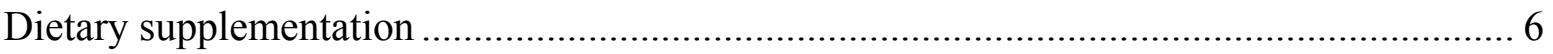

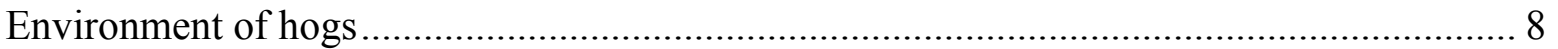

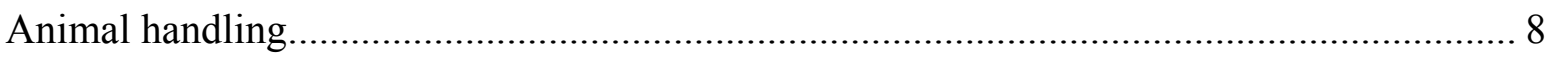

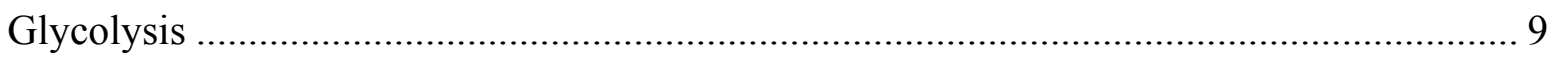

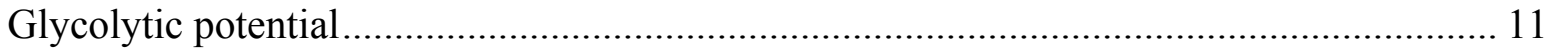

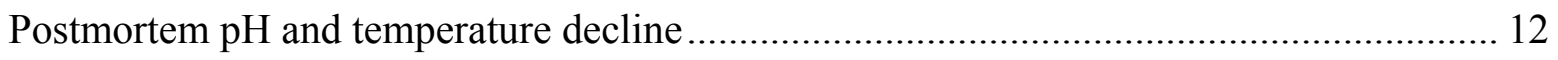

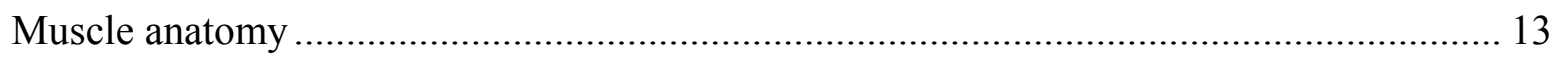

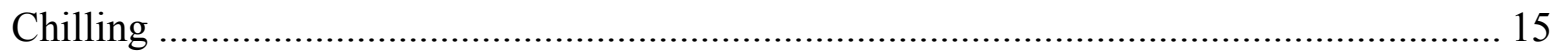

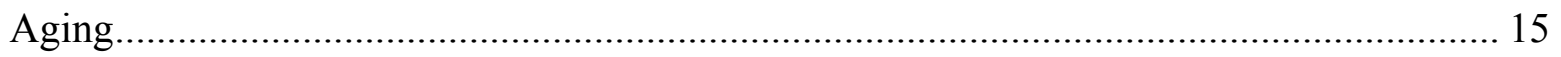

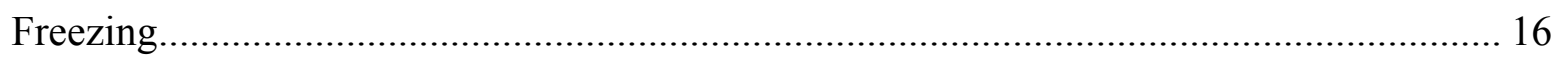

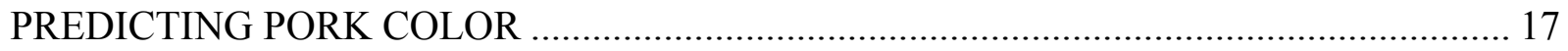

Utilization of $\mathrm{pH}$ measurements ..................................................................................... 17

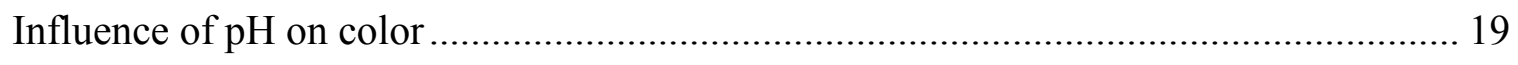

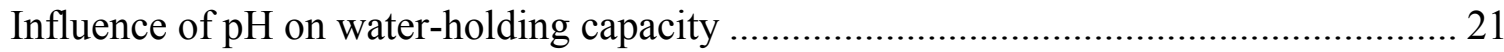

Relationship of water-holding capacity and color .......................................................... 22

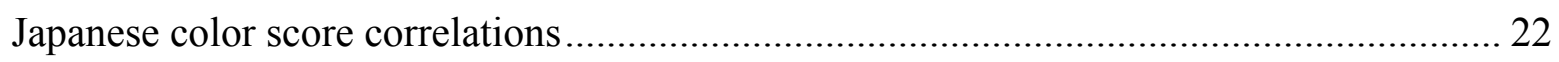

CONSUMER PREFERENCES ................................................................................. 25

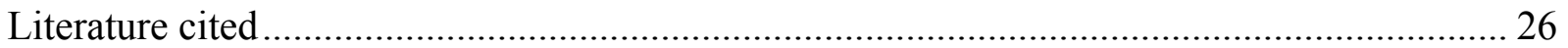

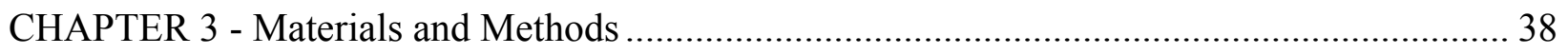




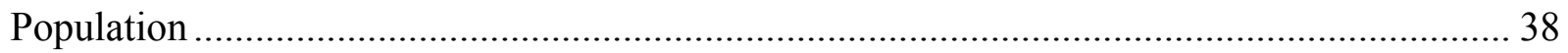

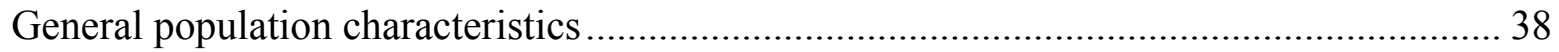

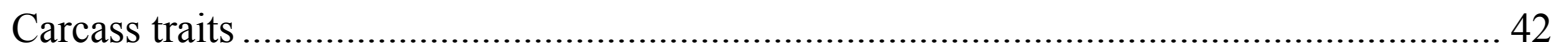

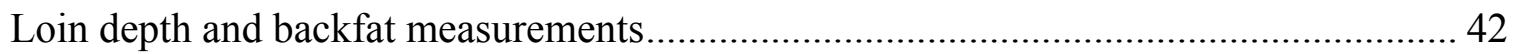

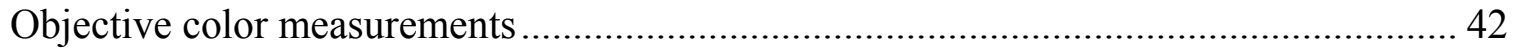

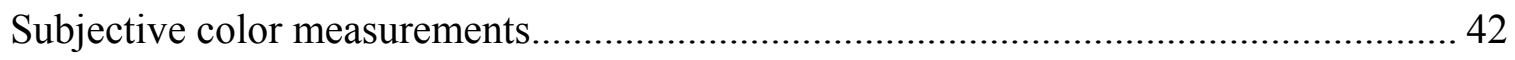

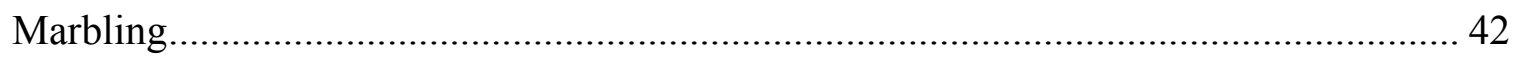

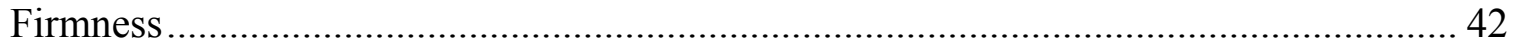

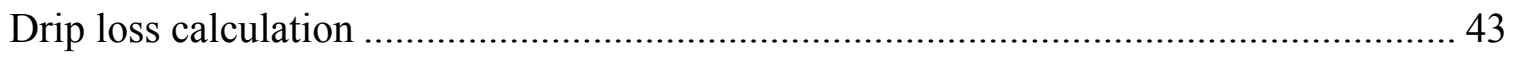

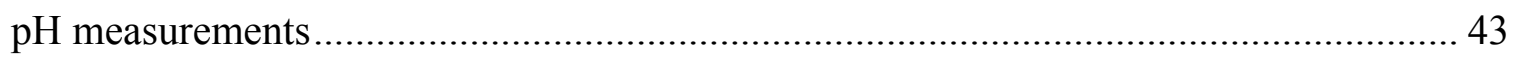

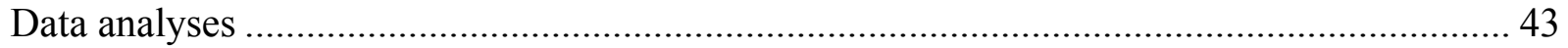

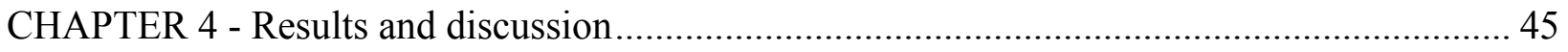

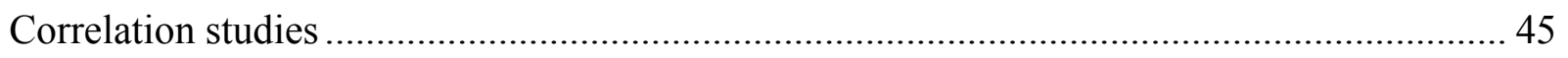

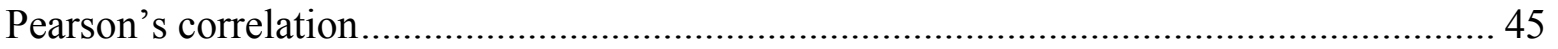

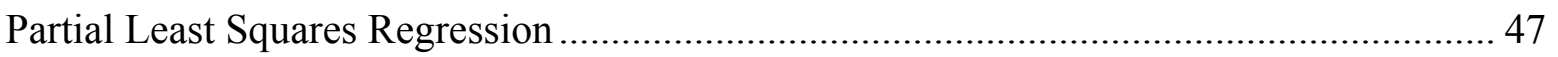

Predictive Modeling (Equation 1)................................................................................. 49

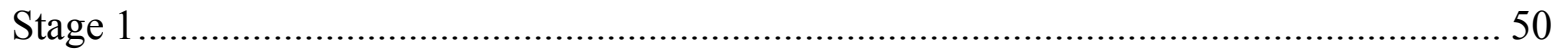

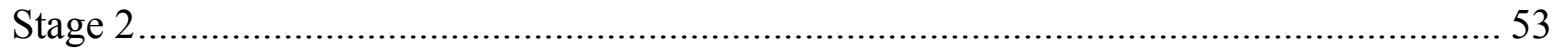

Prediction Equations Utilizing Only Instrumental Color ........................................................ 55

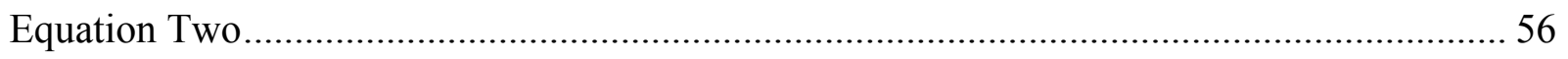

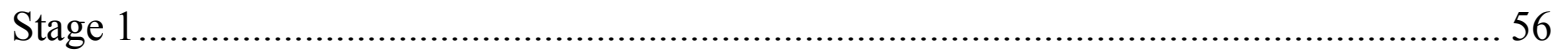

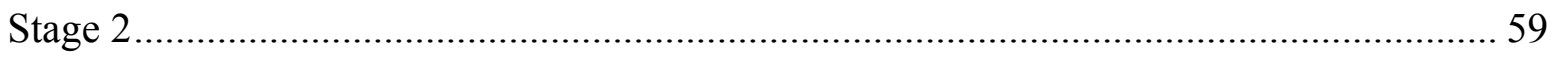

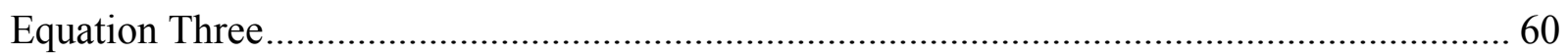

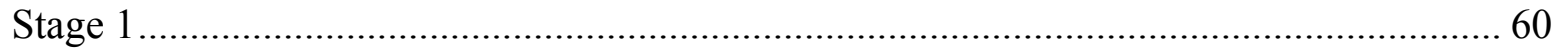

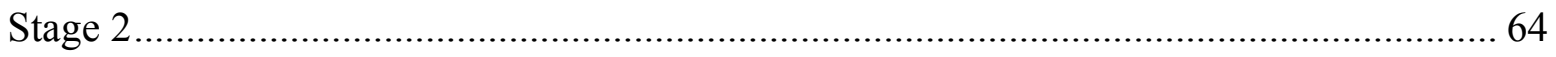

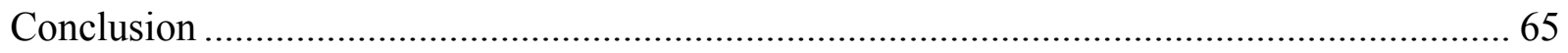

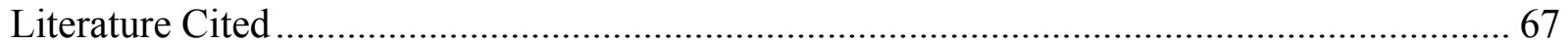

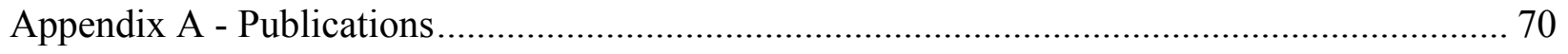

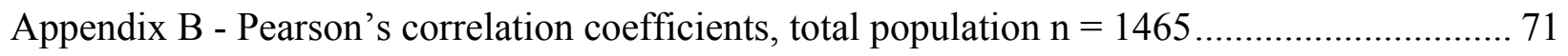




\section{List of Figures}

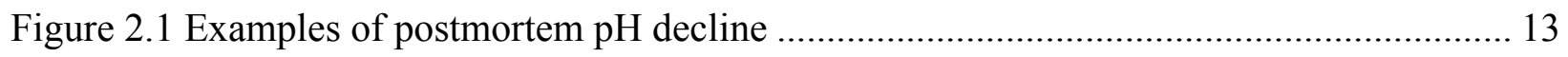

Figure 4.1 Correlation loading of traits found significant by Pearson's correlations .................... 47 


\section{List of Tables}

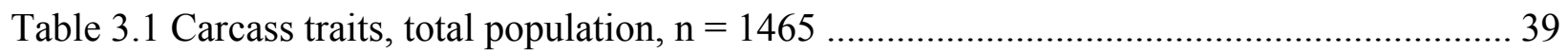

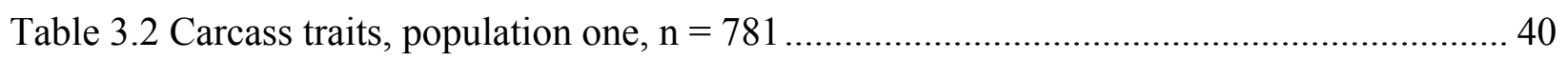

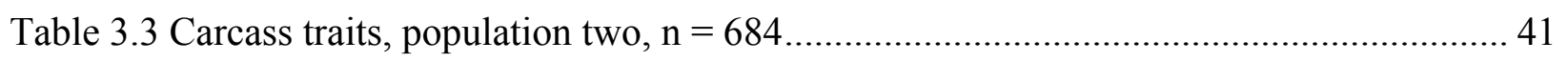

Table 4.1 Pearson's correlation coefficients for Japanese color score and carcass traits, total

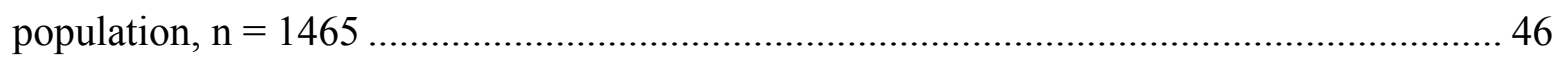

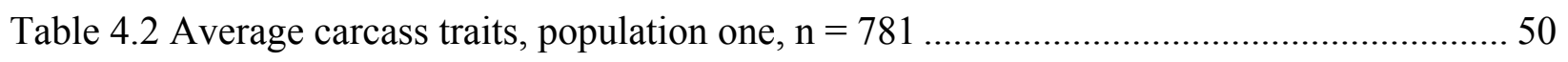

Table 4.3 Number of Japanese color score predicted $\pm 0.25, \pm 0.50$, and \pm 0.75 of the actual

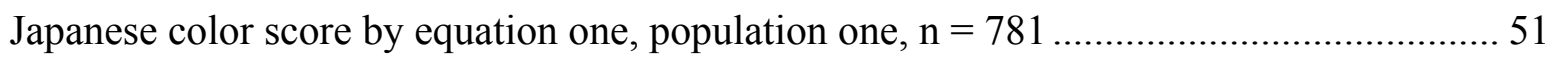

Table 4.4 Number of Japanese color score predicted $\pm 0.25, \pm 0.50$, and \pm 0.75 of the actual

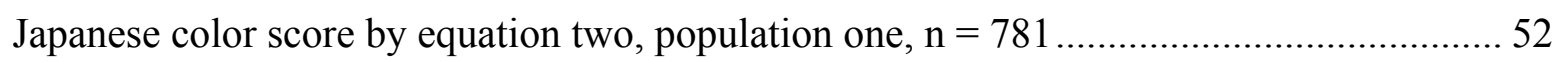

Table 4.5 Number of Japanese color score (JCS) predicted $\pm 0.25, \pm 0.50$, and \pm 0.75 of the actual

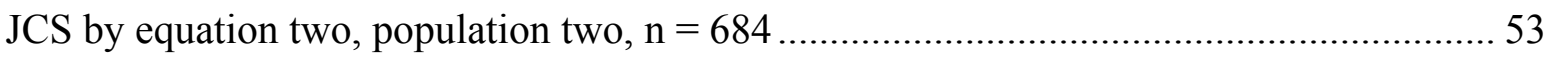

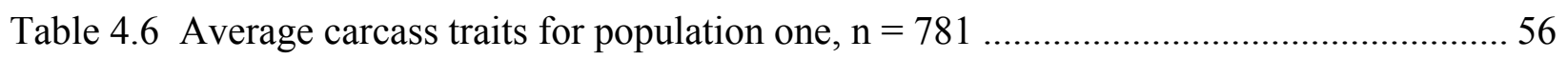

Table 4.7 Number of Japanese color score predicted $\pm 0.25, \pm 0.50$, and \pm 0.75 of the actual Japanese color score by equation one, population one, $\mathrm{n}=781$ 57

Table 4.8 Number of Japanese color score predicted $\pm 0.25, \pm 0.50$, and \pm 0.75 of the actual

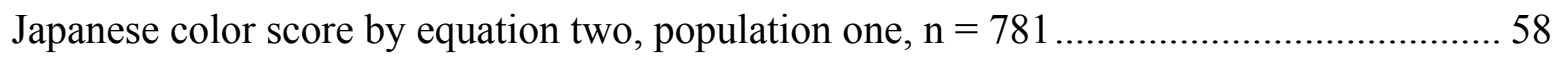

Table 4.9 Number of Japanese color score predicted $\pm 0.25, \pm 0.50$, and \pm 0.75 of the actual

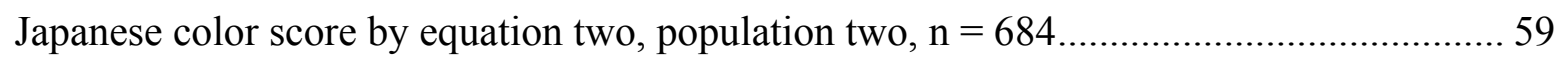

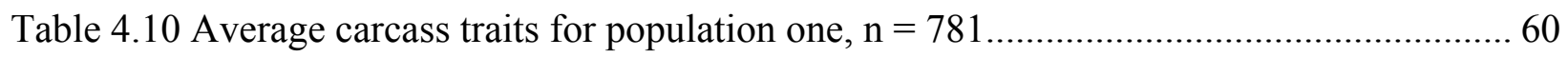

Table 4.11 Number of Japanese color score predicted $\pm 0.25, \pm 0.50$, and \pm 0.75 of the actual Japanese color score by equation one, population one, $\mathrm{n}=781$

Table 4.12 Number of Japanese color score predicted $\pm 0.25, \pm 0.50$, and \pm 0.75 of the actual Japanese color score by equation two, population one, $\mathrm{n}=781$

Table 4.13 Number of Japanese color score predicted $\pm 0.25, \pm 0.50$, and \pm 0.75 of the actual

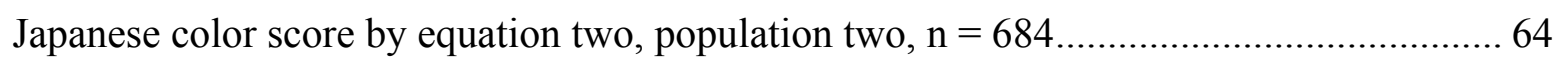

Table 4.14 Summary of prediction equations developed................................................... 65 


\section{Acknowledgements}

I would like to acknowledge and thank the members of my thesis committee: Dr. John

Unruh (chair), Dr. Melvin Hunt, and Dr. Koushik Adhikari. Special thanks to Doc for believing in me as a graduate student and providing guidance and support while I worked to complete my degree. To Hunter, I appreciate getting to work with you on research projects throughout my years as a Wildcat and your enthusiasm for meat science will not be forgotten. Dr. K deserves special thanks as he taught me the ropes of 'scrambling and unscrambling' data and always provided me with much appreciated 'stats humor'. Special thanks go out to all the highlyregarded professors and faculty that I was able to work with and take classes from while I obtained my graduate and undergraduate degrees--you all made my time at Kansas State University an incredible and unforgettable experience.

Secondly, I would like to thank all of those who made this project possible. Thanks to Premium Standard Farms and all the folks who helped me obtain information and data to complete my research. It was a pleasure conducting this study with you all. 


\section{Dedication}

I dedicate this thesis to my family. My parents, Patrick and Barbara Ryan, for their unconditional love, support and encouragement - I am forever grateful. They have given me the guidance I have needed to be successful and have always been there for me, whatever the endeavor or adventure. I would also like to recognize my siblings, Jennifer and Daniel, the most recent additions to my family, Peter and Mackenzie, as well as my aunts and uncles for always providing me with support when it was needed. Furthermore, this thesis is dedicated to my grandparents: Merle and Dorothy Bishop and Alva Ryan. My grandparents have always been a constant supporter of my endeavors and their hard work, professionalism and dedication to their families has made a lasting impression on me; they have instilled many values that I strive to live up to on a daily basis. Additionally, I would like to dedicate this thesis to my extended feed yard family for always being there and pushing me to do my best. Whether it was doctoring cattle, chasing cows or hauling across the nation to shows, you have all taught me a great deal about life. I treasure our countless memories and hours and hours of laughter. Finally, I contribute and dedicate this work to all the others who have become part of my family: those in Manhattan, Des Moines, Fullerton, D.F. and Hermosillo, Mexico, as well as Beijing--I will cherish your

friendship for the rest of my life. 


\section{CHAPTER 1 - Introduction}

Pork quality is determined by visual appearance and the overall eating satisfaction of the meat. Visual appearance is influenced by myoglobin concentration, water-holding capacity (WHC), $\mathrm{pH}$, and the amount of intramuscular fat present (Naumann et al., 1957), while eating satisfaction is a combination of tenderness, juiciness, and flavor (Miller et al., 2000). Cardello (1995) suggested that meat appearance constitutes a dominant factor for consumer purchase attitudes. Many consumers utilize visual appearance (color and the amount of purge) as direct indicators of pork quality as well as indirect indicators of eating quality (Mackey, 1952; Miller et al., 2000). Kropf et al. (1986) stated that consumers primarily use fresh meat color as an indicator of freshness and wholesomeness. Repeated purchases of meat are a result of a positive initial perception as well as overall product satisfaction after consumption. For Asian export markets, consumers are especially conscious and put emphasis on color when making purchases (Cho et al., 2007).

Although recent economic strains have led Japanese consumers to become more costconscious, they're still demanding high-quality pork, the second most popular animal protein in the country. Japanese consumers tend to equate high cost with high quality and have clear ideas about meat quality characteristics that must be met. Japanese consumers are particularly fond of firmer, redder meat (van Heugten, 2001). In a study across several countries, Ngapo et al. (2007) found that when selecting pork, over $45 \%$ of consumers in Japan prefer dark-red lean to light-red lean.

It is estimated that per capita meat consumption will increase by $4.8 \mathrm{~kg}$ between 2005 and 2016 and pork production will increase at a rate of 1.6\% (15.6 million metric tons) to 116.4 million metric tons by 2016 (FAPRI, 2007). In Japan, domestic pork production has been declining over the years due to an aging farmer population, marginal profits, and loss of farmland due to urbanization. Currently, the domestic pork industry supplies nearly two-thirds of Japan's total consumption. However, an increasingly large portion of pork produced in the U.S. is shipped overseas and sold in Japanese markets that demand uniform, high-quality pork. Of the U.S. pork exported to Japan, $70 \%$ is sold to Japanese retail grocery markets, $5 \%$ to the food service sector, and the remaining $25 \%$ for processed products. These markets discriminate 
against lighter-colored cuts with excessive amounts of purge as well as extremely dry, darkcolored cuts (Miller et al., 2000).

Given that Japanese consumers are demanding consistent, high-quality pork, it is necessary to possess the ability to sort carcasses by quality through the use of popular, nondestructive methods such as $\mathrm{pH}$ and spectrophotometric color. The pork industry uses a variety of different meat characteristics to separate fresh pork into quality groups. These characteristics commonly include $\mathrm{pH}$, color, marbling, and firmness. Currently, $\mathrm{pH}$ is the most widely accepted method used to assess pork quality (Chizzolini et al., 1993a, b) and is usually measured objectively with a portable $\mathrm{pH}$ meter, while most of the other characteristics are measured subjectively.

Wismer-Pedersen (1959) concluded that one could potentially identify pale, soft, and exudative (PSE) carcasses by measuring $\mathrm{pH}$ of the medial surface of the longissimus dorsi. Numerous pH methodologies have been investigated extensively (Eikelenboom et al., 1974; Garrido et al., 1994; Chizzolini et al., 1993a, b), with varying degrees of success. The rate and extent of $\mathrm{pH}$ decline of pork muscles has a profound effect on meat paleness, softness, and degree of moisture loss through exudation (Bendall and Swatland, 1988). Andrews et al. (2007) found 24-h pH measurements were useful in predicting color as well as other quality attributes in aged pork loins. Accurate $\mathrm{pH}$ measurements are the key to understanding postmortem muscle glycolysis and subsequently, color (Bendall and Swatland, 1988).

Although processing plants can fairly accurately sort pork carcasses according to basic instrumental and visual observations, there remains a need for processing plants to accurately predict final pork color, especially Japanese color score (JCS), in order to sort carcasses for export. Knowing the best instrumental predictors of JCS as well as being able to place multiple observations into a prediction equation would allow pork plants to more effectively sort carcasses for valuable export markets. The objectives of this study were to explore the relationships between Japanese color score and pork-quality attributes using univariate and multivariate statistics, and then develop a mathematical model to predict Japanese color score using multiple linear regression on pork carcass traits represented by two data sets. 


\section{Literature Cited}

Andrews, B. S., S. Hutchison, J. A. Unruh, M. C. Hunt, J. E. Boyer JR, and R. C. Johnson. 2007. Influence of $\mathrm{pH}$ at $24 \mathrm{~h}$ postmortem on quality characteristics of pork loins aged 45 days postmortem. J. Muscle Foods. 18:401-419.

Bendall, J. R., and H. J. Swatland. 1988. A review of the relationships of $\mathrm{pH}$ with physical aspects of pork quality. Meat Sci. 24:85-126.

Cardello, A. V. 1995. Food quality: Relativity, context and consumer expectations. Food Qual. Prefer. 6:163-170.

Chizzolini, R., E. Noveli, A. Badiani, P. Rosa, and G. Delbono. 1993a. Objective measurements of pork quality: Evaluation of various techniques. Meat Sci. 34:49-77.

Chizzolini, R., E. Noveli, A. Badiani, G. Delbono, and P. Rosa. 1993b. Objective measurements of pork quality: Evaluation of on-line techniques. Meat Sci. 34:79-93.

Cho, S., B. Park, T. Ngapo, J. Kim, E. Dransfield, I. Hwang, and J. Lee. 2007. Effect of meat appearance on South Korean consumers' choice of pork chops determined by image methodology. J. Sensory Studies. 22:99-114.

Eikelenboom, G., D. R. Campion, R. G. Kauffman, and R. G. Cassens. 1974. Early postmortem methods of detecting ultimate porcine muscle quality. J. Anim. Sci. 39:303-308.

Food and agricultural policy research institute (FAPRI). 2007. Overview of the 2007 U.S. and world outlook. http://www.fapri.iastate.edu/outlook2007/text/3Overview.pdf. accessed: October 18, 2007.

Garrido, M. D., J. Pedauyé, S. Bañón, and J. Laencina. 1994. Objective assessment of pork quality. Meat Sci. 37:420-441.

Kropf, D. H., M. C. Hunt, and D. Piske. 1986. Color formation and retention in fresh meat. Page 62 in Proc. Meat Ind. Res. Conf., National Livestock and Meat Board, Chicago, IL.

Mackey, A. O., A. W. Oliver, and S. C. Fang. 1952. Chemical constituents, physical properties of palatability of frozen pork. Food Res. 17:409-418.

Miller, R. K., S. J. Moeller, R. N. Goodwin, C. L. Lorenzen, and J. W. Savell. 2000. Consistency in Meat Quality. Pages 566-579 in Proc. 46th Int. Congr. Meat Sci. Technol. Buenos Aires, Argentina. 
Naumann, H. D., V. J. Rhodes, D. E. Brady, and E. R. Kiehl. 1957. Discrimination techniques in meat acceptance studies. J. Food Technol. 2:123-132.

Ngapo, T. M., J. F. Martin, and E. Dransfield. 2007. International preferences for pork appearance: II. Factors influencing consumer choice. Food Qual. Pref. 18:139-151.

van Heugten, E. 2001. Understanding Pork Quality. Vol. 24, No. 3, North Carolina State Univ. Swine News, Raleigh, NC.

Wismer-Pedersen, J. 1959. Quality of pork in relation to rate of $\mathrm{pH}$ change post-mortem. Adv. Food Res. 24:711-718. 


\section{CHAPTER 2 - General Review of Literature}

\section{FACTORS AFFECTING PORK COLOR}

Pork quality traits are influenced by several antemortem and postmortem factors (Honikel, 1987; Warriss, 1987; Sellier and Monin, 1994) making the prediction of ultimate pork quality difficult. Many physical and biochemical factors can be evaluated in an attempt to assess meat quality: genetics, dietary supplementation, environment, animal handling, glycolysis, glycolytic potential (estimate of the muscle glycogen concentration at harvest), postmortem $\mathrm{pH}$ and temperature decline, muscle anatomy, chilling, aging, and freezing.

Between harvest and shipping, many physical and biochemical reactions occur which can adversely affect meat quality. Therefore, when developing a prediction equation, it is necessary to possess an understanding of the most accurate and objective indicators of pork color, especially factors that are easily measured and can determine final pork quality early postmortem.

\section{Genetics}

A survey conducted by Kauffman et al. (1986) indicated approximately one-quarter of the U.S. pork produced was either pale, soft, and exudative (PSE) or dark, firm, and dry (DFD). Genetic selection is the initial step in reducing variation and improving pork quality. Poor quality resulting from certain genetic lines and breeds has been linked to rapid muscle glycolysis and a rapid $\mathrm{pH}$ decline (Monin and Sellier, 1985). Two major genes that affect pork quality have been identified as the Napole (RN) and halothane (HAL) genes (Eikelenboom and Nanni Costa, 1988). Stress-susceptible pigs often have meat with extreme protein denaturation, pale-colored lean, decreased water-holding capacity (WHC), and lower cooked ham yields.

In 1985, Monin and Sellier reported a "Hampshire effect" that produced meat with a normal rate of $\mathrm{pH}$ decline, but an extremely low ultimate $\mathrm{pH}$ in all muscles, especially the longissimus dorsi and ham muscles. Later, LeRoy et al. (1989) found the "Hampshire effect" was caused by the Napole gene (RN-, dominant allele; rn+, recessive allele). The RN gene increases the glycogen content by about 70\% in muscles (Estrade et al., 1993) and decreases protein content by 5 to 7\% (Monin et al., 1986). Napole carriers have also been shown to have 
lower processing quality, producing inferior yields and quality in comparison to normal pork (Lundstrom et al., 1996). Other research has suggested that the $\mathrm{rn}+/ \mathrm{rn}+$ genotypes (non-carriers for the Napole gene) resulted in darker loins than $\mathrm{RN}-/ \mathrm{rn}+$ (carriers for the Napole gene; Moeller et al., 2003).

Numerous studies have concluded that fresh pork color is detrimentally affected by the presence of the HAL gene (Channon et al., 2000; Eggert et al., 2002; Fabrega et al., 2002; Fernandez et al., 2002; Fisher et al., 2000; Moelich et al., 2003; Van Oeckel et al., 2001; Velarde et al., 2001) and hogs with this mutation often have increased lean meat yield but tend to result in low-quality PSE pork.

In 2004, Brewer et al. evaluated several sire lines (Duroc, Synthetic, Duroc/Landrace, Pietrain, Duroc/Hampshire and large white) and reported that genetic line affected loin chop lightness, pinkness, a*, and two-toning. Similarly, Edwards et al. (2003) suggested that Duroc progeny had more favorable visual color, higher $\mathrm{pH}$, and increased redness than Pietrain-sired pigs.

In summary, genetic selection is the initial step in reducing variation and improving pork quality. Wise genetic selection can help reduce the possibility of poor pork quality by selecting against the RN and HAL genes. Elimination of these genes generally results in increased processing yields as well as more desirable visual color and shelf life.

\section{Dietary supplementation}

Dietary supplementation has been examined as a means of improving pork color. Supplementing diets of growing-finishing pigs with a manganese amino acid complex improved pork color (Apple et al., 2004). Similarly, adding magnesium mica to growing-finishing diets improved pork color ( $\mathrm{a}^{*}$, chroma, and visual assessment; Apple et al., 2000). Magnesium can minimize stress before harvest and promote the uptake of high-energy phosphates, which are involved in glycolysis (Frederick et al., 2004). Wilborn et al. (2004) speculated that feeding vitamin D3 might elevate intracellular calcium levels, promote slow-twitch fiber expression, and increase oxidative muscle metabolism. Although the mechanism remains unclear, vitamin D3 improved pork color which may benefit pork intended for shipment to export markets (Wiegand et al., 2002; Wilborn et al., 2004). 
It is generally accepted that a period of feed withdrawal prior to harvest reduces the risk of development of meat-quality defects. Feed withdrawal can enhance meat quality by reducing the amount of total carbohydrate available for postmortem conversion of glycogen to lactic acid (DeSmet et al., 1996). Muscle quality improvements from overnight feed withdrawal at the plant have been reported (Jones et al., 1985) as increased ultimate $\mathrm{pH}$, loin color intensity, and waterholding capacity. Eikelenboom et al. (1991) found that pigs held off feed (but not water) for a minimum of $12 \mathrm{~h}$ before harvest resulted in a lower incidence of PSE carcasses. Murray et al. (1989) reported that a $24 \mathrm{~h}$ or $48 \mathrm{~h}$ fast significantly reduced the frequency of PSE in stresssusceptible pigs. A review by Ellis et al. (1999) outlined a series of investigations regarding the impact of feed withdrawal from pigs with high and low glycolytic potential prior to harvest. One of these studies showed that withholding feed 36 to $60 \mathrm{~h}$ prior to harvest increased ultimate $\mathrm{pH}$ and improved lean color.

However, the muscle quality advantages from feed withdrawal are not consistent in the scientific literature. DeSmet et al. (1996) found overnight feed withdrawal to have no effect on meat quality for all PSE related traits in normal, stress carrier, and stress positive pigs. Becker et al. (1989) found no relationship between feed withdrawal up to $72 \mathrm{~h}$ and ultimate pork quality. See et al. (2001) found feed withdrawal prior to shipment improved the color of the longissimus dorsi as indicated by linear increases in Japanese color score (JCS) and linear decreases in Minolta $\mathrm{a}^{*}$ measures over increasing feed withdrawal periods.

Ractopamine hydrochloride (Paylean ${ }^{\circledR}$ ) is a feed supplement that is commonly used by U.S. swine producers to improve feed efficiency, average daily gain, carcass dressing percentage, and carcass fat-free lean content, while having little to no effect on pork quality. When investigating the effect of Paylean ${ }^{\circledR}$ on carcass quality, Stahl et al. (2007) found no affect on Japanese color score, instrumental L* and $\mathrm{b}^{*}$ as well as ultimate $\mathrm{pH}$ of the longissimus.

In summary, dietary supplementation has been investigated as a means of improving pork color. Feeding both manganese amino acid complexes and vitamin D3 has been shown to improve pork color. In addition, it has been found that a period of feed withdrawal prior to harvest reduces the risk of development of meat quality defects and enhances meat quality especially through improvements in lean color. 


\section{Environment of hogs}

The effects of pre-harvest environment, particularly housing and pen space, may affect pork color. Although neither birth nor rearing environment influenced loin darkness or yellowness, pigs born and reared outdoors had redder loins than pigs born and reared indoors (Gentry et al., 2004). Loins from pigs born and finished outdoors were higher in Type I and IIA fibers, and the authors suggested that rearing pigs in an outdoor production system might increase muscle redness by delaying the conversion of IIA to IIB muscle fibers. They also found that loins from barrows finished with inadequate pen space were darker than loins from barrows finished with adequate pen space; the difference in loin color was attributed to a reduced response to stress at harvest.

In summary, environment has been shown to affect pork color. Pigs reared in outdoors environments have been found to have redder loins. In addition, barrows finished with inadequate pen space had darker loins than loins from barrows finished with adequate pen space. Differences in loin color have been attributed to the delay in conversion of muscle fiber types and a reduced response to stress at harvest.

\section{Animal handling}

Animal handling is an important antemortem factor that can affect pork quality. Even with superior genetics, inferior pork quality can occur if hogs have been improperly handled. Animals that are well rested and relaxed prior to harvest generally have more acceptable carcass quality. It is recommended that animals be treated with proper handling throughout the rearing stages, transportation, and harvest. During animal rearing, hogs should be introduced to humans and noise as much as possible to avoid nervousness prior to harvest (Grandin, 2000).

Transportation conditions affect postmortem meat quality by provoking stress or animal fatigue. During transportation, adequate ventilation and proper insulation should be provided (Grandin, 1999). It is recommended that animals be scheduled for delivery to a processing facility at night or early morning, and upon arrival at the harvesting facilities, animals should be unloaded as quickly as possible and rested for 6 to $12 \mathrm{~h}$ prior to harvest (Grandin, 1999).

Rosenvold and Andersen (2003) reported that pre-harvest stress did not affect $24 \mathrm{~h}$ color and $\mathrm{pH}$ but increased the degree of bloom. They found a stress-induced increase in earlypostmortem longissimus temperature, which promotes denaturation of proteins involved in 
oxygen consumption, resulted in greater surface oxygenation due to less competition for oxygen by enzymes. Conversely, in the biceps femoris and semitendinosus, this stress-related elevation of early-postmortem muscle temperature may inactivate metmyoglobin reductase, which subsequently negates the benefits of color stability during display. Thus, in pigs lacking the genetics conductive to rapid postmortem $\mathrm{pH}$ decline, muscle temperature influenced color and color stability more than $\mathrm{pH}$.

Finally, pre-harvest handling and stunning method also influenced pork color (Channon et al., 2000). Pigs stunned with carbon dioxide had loins that were darker and less yellow than loins from pigs electrically stunned (Velarde et al., 2001). Seasonal effects on instrumental color values have been investigated. $L^{*}$ values (paler muscle in the summer) have been attributed to changes in the calcium release channels (Kuchenmeister et al., 2000). Others have reported that in addition to weather, seasonal increases in demand, production, and harvest rate may detrimentally affect pork color (O'Neill et al., 2003).

Overall, improper animal handling can detrimentally impact pork carcass quality and improvements in pork quality can be observed when hogs are handled properly. Increased color stability during display as well as decreased incidence of pale, soft, and exudative or dark, firm, and dry carcasses will result when hogs are well rested and relaxed prior to harvest. Although difficult to consistently put into practice, improved animal handling practices, reduced animal stress, and the use of the best possible genetic lines would greatly reduce the amount of quality nonconformities seen in the pork industry today.

\section{Glycolysis}

Glycolysis is one of the most significant postmortem changes in the conversion of muscle to meat. Glycolysis is the enzymatic conversion of glycogen, by way of phosphate derivatives, to pyruvic or lactic acid and energy in the form of high-energy phosphate bonds of adenosine triphosphate (ATP; Hedrick et al., 1994). It is characterized by the lowering of muscle $\mathrm{pH}$ due to the accumulation of lactic acid within the muscle. Normal glycolysis continues in muscles until either glycogen levels are depleted or a low muscle $\mathrm{pH}$ (approximately 5.4 to 5.5) is reached within 6 to $12 \mathrm{~h}$, whereas the completion of rigor occurs within 4 to $6 \mathrm{~h}$ (Briskey and Wismer-Pedersen, 1961). Low pH $(<5.4)$ causes the inactivation of many enzymes affecting the 
breakdown of glycogen, ceasing the ability to produce ATP (Hedrick et al., 1994; Sahlin et al., 1978).

One of the most commonly used measurements to identify the rate and extent of glycolysis is hydrogen ion concentration, measured as $\mathrm{pH}$. Both the rate and extent of $\mathrm{pH}$ decline are influenced by both intrinsic factors (species, age, type and location of muscle, sex, and genetics) and extrinsic factors (diet, stress, post mortem handling, and immobilization method). These extensive factors have a dramatic effect on quality (Jeremiah et al., 1991; Lawrie, 1991; Hedrick et al., 1994) and controlling these factors can dramatically improve meat quality.

Ultimate $\mathrm{pH}$ refers to the final $\mathrm{pH}$ attained, either by the depletion of glycogen or by enzyme inactivation (Bendall, 1973), which is usually attained 22 to $24 \mathrm{~h}$ postmortem. Normal $\mathrm{pH}$ decline in pork muscle is a gradual curvilinear decrease from an approximate $\mathrm{pH}$ of 7.4 (living muscle) to a pH of 5.6 to 5.8 within 6 to $8 \mathrm{~h}$ postmortem. At $24 \mathrm{~h}$ postmortem, pork muscle should reach an ultimate $\mathrm{pH}$ in a range of 5.4 to 5.7 (Hedrick et al., 1994; Lawrie et al., 1958a, b; Bendall, 1973). Muscles with a normal $\mathrm{pH}$ decline will appear as a normal reddishpink color with optimum exudate retention and adequate muscle firmness (Briskey and WismerPedersen, 1961). Deviation from a normal $\mathrm{pH}$ decline has the potential to create carcasses that are heterogeneous in quality.

Rapid temperature reduction can improve the ultimate quality of pork from animals predisposed to a rapid glycolytic decline (Borchert and Briskey, 1964). Quality can be improved by rapidly reducing the temperature in a rapid glycolytic animal. However, with rapid cooling, the risk of cold shortening (and subsequent toughening) may exist.

In summary, post-mortem glycolysis is responsible for the drop in $\mathrm{pH}$. Glycogen stores in muscle are converted into glucose, which is subsequently converted into lactic acid in the absence of oxygen. If glycogen stores are high and the temperature of the carcass is relatively high, glycolysis will proceed at a fast rate and the ultimate $\mathrm{pH}$ will be low. When glycolysis ceases, either because glycogen stores are depleted or because the $\mathrm{pH}$ has reached a point at which enzymes become inactive, $\mathrm{pH}$ is typically 5.5 . Muscles with a normal $\mathrm{pH}$ decline will appear as a normal reddish-pink color with optimum exudate retention and adequate muscle firmness. Quality can be improved in a rapid glycolytic animal by rapidly reducing temperature however, cold shortening may result. 


\section{Glycolytic potential}

The extent of glycolysis depends on muscle glycogen levels prior to harvest (Bendall, 1973; Warriss et al., 1989) and can influence the quality of pork. One gram of glycogen has the capability to bind 2 to $4 \mathrm{~g}$ of water (Greenleaf et al., 1969), which is freed during glycogenolysis. Due to the difficulty in directly measuring glycogen levels in muscle, Monin and Sellier (1985) proposed to measure the glycogen potential of animals, which is the sum of the compounds likely to produce lactic acid postmortem. Glycolytic potential is calculated as follows: $2 \times$ (glycogen + glucose + glucose-6-phosphate) + lactate. These compounds have the ability to affect glycogen levels, ultimately resulting in large variations in meat quality (Fernandez and Tornberg, 1991).

High glycogen levels can result in meat with lower ultimate $\mathrm{pH}$, often leading to PSE meat. However, high levels of glycogen above a threshold may not affect ultimate $\mathrm{pH}$ (Fernandez and Tornberg, 1991). Meat with lower ultimate $\mathrm{pH}$ often resulted from animals that were carriers of the RN- allele (Napole gene; LeRoy et al., 1989; Monin and Sellier, 1985). In addition, factors associated with aggressive behavior, as seen in boars, prior to harvest can result in glycogen depletion and higher ultimate $\mathrm{pH}$ than barrows and gilts (Lundstrom et al., 1987).

Hamilton et al. (2003) reported that glycolytic potential was moderately correlated to longissimus $\mathrm{L}^{*}$ values $(\mathrm{r}=0.23$ antemortem, $\mathrm{r}=0.31$ postmortem). In addition, free glucose content was related to muscle darkening $(\mathrm{r}=0.52)$. The authors suggested that $\mathrm{L}^{*}$ values increase 0.99 and 1.32 units for every one standard deviation in ante- and postmortem glycolytic potential, respectively. As a result, they found longissimus quality to be inversely related to glycolytic potential and free glucose. Moeller et al. (2003) also reported positive correlations between longissimus glycolytic potential and $\mathrm{L}^{*}(\mathrm{r}=0.33)$. Glycolytic potential was correlated to $L^{*}(r=0.40)$ and $b^{*}(r=0.43)$, which suggests that increases in glycolytic potential promote acidity, paleness (lower $\mathrm{L}^{*}$ values), and yellowness (greater $\mathrm{b}^{*}$ values; Meadus and MacInnis, 2000). However, Hamilton et al. (2002) reported that glycolytic potential affected ultimate $\mathrm{pH}$ but not longissimus color. Ultimate lactate level and $\mathrm{L}^{*}$ were linearly related, with increased paleness during storage resulting from higher lactate levels (Juncher et al., 2001). 


\section{Postmortem pH and temperature decline}

The rate of postmortem glycolysis and subsequent $\mathrm{pH}$ decline can vary within a muscle, among muscles within a carcass, and among carcasses (Tarrant and Mothersill, 1977). Slow rates of $\mathrm{pH}$ decline are noted in superficial, rapidly chilled portions of the carcass, while deeper, more slowly chilled portions have faster $\mathrm{pH}$ declines. These different $\mathrm{pH}$ decline rates result because the biochemical changes occurring postmortem are temperature dependent; they occur faster when temperature is elevated. These differing $\mathrm{pH}$ decline rates ultimately lead to heterogeneous quality within the same muscle (Tarrant and Mothersill, 1977). This lack of consistent quality is particularly evident within the semimembranosus muscle in pork.

Muscle that experiences a gradual, intermediate rate of $\mathrm{pH}$ decline is normal in appearance and protein functionality. Animals that have an adequate supply of glycogen postmortem and experience minimal stress and excitement prior to harvest generally have muscle that undergoes an intermediate $\mathrm{pH}$ decline as shown in Figure 2.1. This occurs when a slower temperature decline within the muscle inhibits a rapid $\mathrm{pH}$ decline. Neither $\mathrm{pH}$ nor temperature decline occurs too quickly or too slowly. Typically, color and protein functionality are not affected adversely under these conditions.

The top curve in Figure 2.1 represents a situation where an animal has lower than normal glycogen remaining in the muscle. Low glycogen levels result in little lactic acid production, and $\mathrm{pH}$ decline is limited. Ultimate $\mathrm{pH}$ in this situation can range from 6.3 to 7.0 , and almost always results in DFD pork.

Rapid $\mathrm{pH}$ decline rates Figure 2.1 while the muscle temperature remains elevated during the first few hours postmortem lead to increased protein denaturation, reduced water-holding capacity, a softer texture, and a paler color (Follett et al., 1974). As glycogen is broken down, lactic acid accumulates quickly leading to a rapid drop in $\mathrm{pH}$ while temperature remains elevated. After $24 \mathrm{~h}$, the difference between lactate and glycogen in animals with rapid $\mathrm{pH}$ declines and animals with normal $\mathrm{pH}$ declines is not significant. It is important to note that the ultimate $\mathrm{pH}$ of PSE meat may not be different than the ultimate $\mathrm{pH}$ normal meat ( $\mathrm{pH}$ 5.6); the critical difference is the amount of time that passes until the ultimate $\mathrm{pH}$ is attained.

In summary, postmortem biochemical changes in a carcass are temperature dependent, occurring faster when temperature is elevated. Rate of postmortem glycolysis and subsequent $\mathrm{pH}$ decline vary from carcass to carcass and result in heterogeneous pork quality. Carcasses that 
undergo a gradual, intermediate rate of $\mathrm{pH}$ decline will generally be normal in appearance and protein functionality, while carcasses that have a rapid $\mathrm{pH}$ decline rate while the muscle temperature remains elevated early postmortem will generally be pale, soft, and exudative.

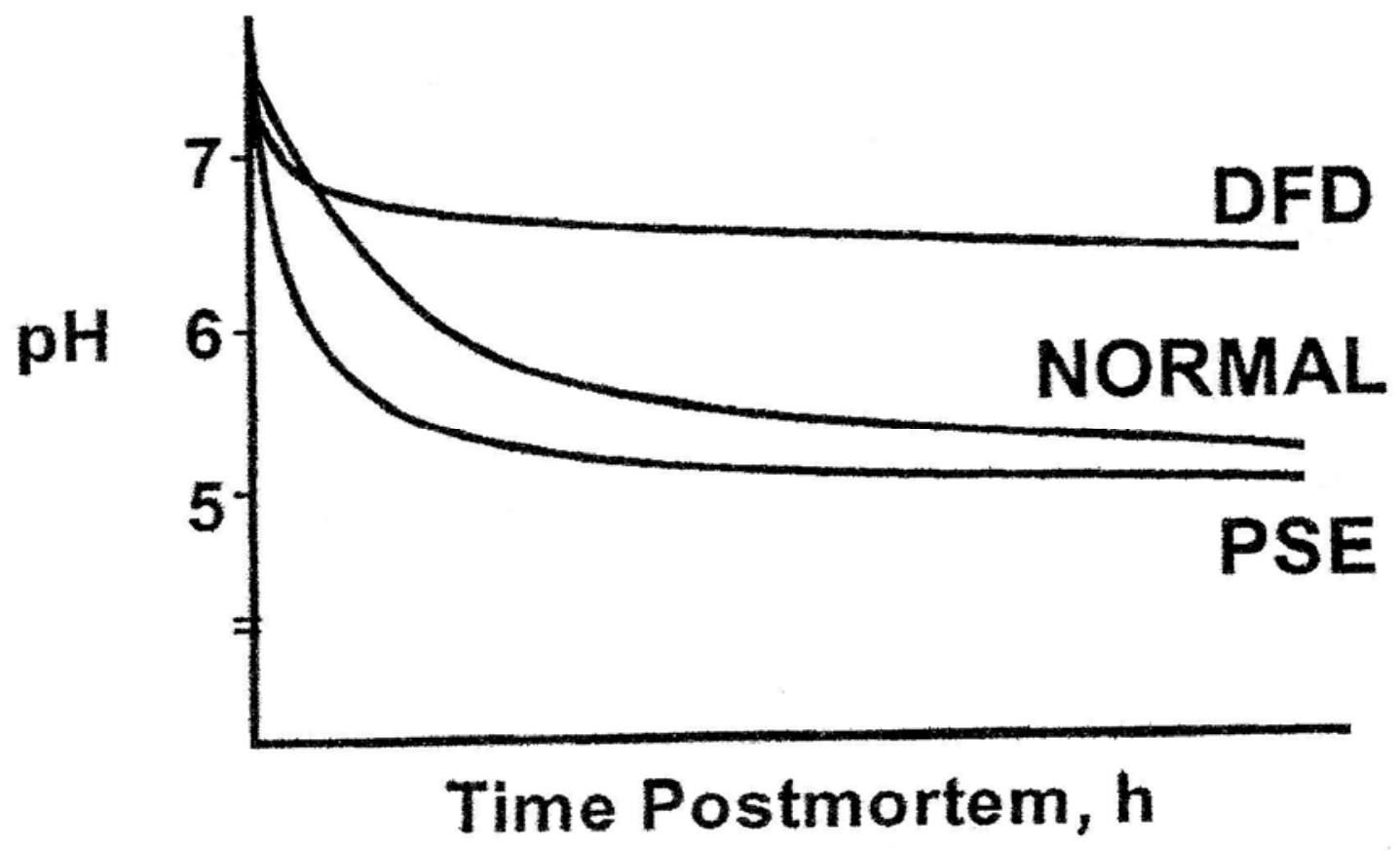

Figure 2.1 Examples of postmortem pH decline

Adopted from Briskey, E. J. (1964). Etiological status and associated studies of pale, soft, exudative porcine musculature. Adv. Food Research. 13:89-168.

\section{Muscle anatomy}

Muscle fiber type and location within an animal, as well as location within a muscle can have a dramatic effect on pork quality. Following harvest, muscles in a carcass are subjected to different temperature/pH regimes during postmortem glycolysis, affecting essential reactants in the oxidation of myoglobin and/or reduction of metmyoglobin to differing degrees (Lawrie, 1991). Muscles most likely to develop PSE or DFD characteristics are the longissimus lumborum, semimembranosus, biceps femoris, gluteus medius, and the lateral portion of the 
semitendinosus muscles (Warner et al., 1993). Aerobic muscles such as the quadriceps (vastus medialis, vastus intermedius, vastus lateralis, rectus femoris) are composed of more red-type fibers and are less susceptible to becoming pale, soft, and exudative due to greater concentrations of reducing enzymes (Kropf, 1993). Muscles with greater oxidative activity are typically less color stable (O'Keefe and Hood, 1980; Renerre and Labas, 1987).

The properties of a particular muscle are dependent on the types of myofibrils present (Cassens et al., 1992). Rae and Price (1986) suggested that the degree to which DFD is expressed is partially due to the muscle type and location. Three major fiber types are slowtwitch oxidative, fast-twitch glycolytic, and fast-twitch oxidative-glycolytic (Peter et al., 1972). "Red" muscles have higher concentrations of slow-twitch oxidative fibers, which have higher myoglobin concentrations. In addition, these fibers contain a large number of mitochondria, and thus, tend to discolor more rapidly due to the higher mitochondria content and enzyme activity. In contrast, fast-twitch oxidative-glycolytic fibers have less mitochondria and a higher level of high-energy phosphates and glycogen. Muscle fibers that are more reliant on glycolytic pathways and that contain less myoglobin (IIb) to store oxygen may shift to anaerobic metabolism earlier, thereby accelerating the rate of postmortem $\mathrm{pH}$ decline, resulting in greater color stability.

Location within a muscle may also play a role in ultimate meat quality. Homm et al. (2006) concluded quality varies considerably within boneless pork loin with the highest quality chops on the posterior end of the boneless loin. Posterior chops were the most tender, had the highest cooking yields, contained a high $\mathrm{pH}$, and had a high percent extractible lipid content. In addition, centrally located chops were found to be more uniform in color, firmness, and marbling, while anterior chops were more variable in quality than center loin and posterior chops. Anterior chops were darker and softer with more exudate than center loin or posterior chops.

In summary, muscle type (as reflected by fiber type) and location within an animal, as well as location within a muscle can have a dramatic effect on pork quality. In general, the properties of a particular muscle are dependent on the type of myofibrils present. Muscles with more slow-twitch oxidative fibers tend to discolor more rapidly while muscles with a higher concentration of fast-twitch oxidative-glycolytic fibers tend to be more color stable. Chop location within a muscle can also play a role in pork quality. 


\section{Chilling}

Variations in post-harvest chilling can produce detectable differences in pork quality, especially color and tenderness. Muscles within a carcass have varying rates of postmortem temperature decline according to their proximity to the interior of the carcass and the amount of fat cover present (Briskey, 1964). The rate of postmortem glycolysis tends to be higher in muscles that chill slower and are more interior within the carcass (Bate-Smith and Bendall, 1949). Bendall and Wismer-Pedersen (1962) showed muscles that were allowed to go into rigor mortis at a constant temperature of $37^{\circ} \mathrm{C}$ always became PSE. MacDougall (1982) cooled an intact hindquarter at two different rates and found that the interior was paler in color when the hindquarter was slow chilled.

The rate of chilling affects the final contraction state and overall tenderness of meat as it passes into rigor mortis (Wheeler and Koohmarie, 1994). Rapid chilling of muscles prior to rigor creates an effect known as cold shortening (or cold toughening), which has a negative effect on tenderness. During rapid chilling prior to rigor, sacrcomeres are shortened considerably; consequently, the result is a denser muscle fiber and extremely tough meat (Feldhusen and Kühne, 1992).

In review, variations in postmortem chilling can produce detectable differences in pork quality. Muscles (and muscle areas) that are more interior within the carcass chill slower and tend to have a higher rate of postmortem glycolysis, which generally results in poor pork quality. Too rapid of a chill after harvest may result in cold shortening, which negatively impacts pork tenderness.

\section{Aging}

Following rigor, carcasses are often cut into primals or subprimals and stored in vacuumpackages. During storage, meat undergoes an aging process that can affect meat quality. Aging at higher temperatures has been shown to decrease color stability and promote bacterial growth. A higher storage temperature causes greater oxygen scavenging by residual respiratory enzymes, which leads to low oxygen tensions and facilitates the autoxidation of myoglobin (Renerre, 1990). Meat stored at $10^{\circ} \mathrm{C}$ was found to discolor two to five times faster than meat stored at $0^{\circ} \mathrm{C}$ (O'Keefe and Hood, 1980). Therefore, meat should be stored near $0^{\circ} \mathrm{C}$ in order to improve color and color stability. 
In review, high storage temperatures move the brown metmyoglobin layer closer to the surface causing a more visible brown appearance. In contrast, lower temperatures promote the penetration of oxygen into the surface of meat because the oxygen utilizing enzymes are less active, which maintains myoglobin in its oxygenated form.

\section{Freezing}

Freezing is an excellent means of preservation and is especially useful when shipping meat products to overseas markets, but in the end, freezing generally has unfavorable effects on meat quality, especially that of visual appearance. The color of frozen meat is controlled by the freezing rate, storage temperature and light intensity during display, as well as method of packaging (Kropf, 1980). Renerre (1990) stated that meat frozen slowly is dark in color while meat frozen in liquid nitrogen (frozen very rapidly) is pale in color. Faster chilling causes smaller intracellular ice crystals to form, which scatters more light than larger, extra cellular ice crystals (Jakobsson and Bengtsson, 1973).

The rate of freezing can have a dramatic effect on purge and muscle tenderness. There have been conflicting views on the effects of freezing on the amount of purge resulting from frozen storage. Some studies have shown that increasing freezing rates can decrease the amount of drip (Hamm and Detherage, 1960), while others have found that freezing rates have no affect on the amount of purge. It is believed that during the freezing process, ice crystals form between and within muscle fibers. When freezing rates are slow, large ice crystals form, causing extensive physical damage to the muscle fibers (Martino et al., 1998). As slowly frozen meat is thawed, a large amount of moisture is leaked out of the damaged muscle fibers, resulting in purge (Ngapo et al., 1999a, b, c). On the other hand, a more rapid freezing rate still results in ice crystal formation, however, the size of the crystals are smaller. Smaller ice crystals cause less damage to the muscle fibers, ultimately resulting in less purge.

In general, freezing has unfavorable affects on meat quality, especially that of visual appearance. Meat frozen rapidly is darker in appearance than meat frozen slowly. Slowlyfrozen meat results in the formation of large ice crystals which causes extensive damage to muscle fibers. Once slowly-frozen meat is thawed, the ultimate result is excess drip loss. A more rapid freezing rate results in the smaller formation of ice crystals which are less damaging to muscle fibers and result in less drip loss. 


\section{PREDICTING PORK COLOR}

For practical reasons, it is desirable for packing plants to accurately, quickly, noninvasively, and economically assess pork quality characteristics early postmortem. Abattoirs often utilize $\mathrm{pH}$ and instrumental color measurements to estimate quality characteristics (Chizzolini et al., 1993a, b; Wulf et al., 1997; Yu and Lee, 1986; Fjelkner-Modig and Rudérus, 1983; Bouton et al., 1973; Herring et al., 1971) and when exporting pork to Japan, abattoirs often sort carcasses according to Japanese color score (Walstra et al., 1977). The Japanese color scores are comprised of six color blocks that are equally spaced within the Hunter Lab scale (Nakai et al., 1975). In 1999, the NPPC suggested that the $L^{*}$ values for describing the range of light-color quality pork (Japanese color score 1) to dark-color quality pork (Japanese color score 6)—-should be approximately 61, 55, 49, 43, 37, and 31, respectively (NPPC, 1999).

Based on past observations, several researchers found the major loin (longissimus thoracis and longissimus lumborum) and ham muscles (semimembranosus, biceps femoris, gluteus medius, and semitendonosus) were best suited for assessing pork color (Beecher et al., 1965; Warner et al., 1993). However, early and accurate prediction of pork color is a difficult task. Early postmortem, most quality properties have not been completely expressed biochemically or physically (Wulf et al., 1997). Furthermore, early postmortem, there are few cut surfaces on which quality characteristics can be observed or measured instrumentally. Instrumental procedures that estimate pork quality early postmortem have been developed (Chizzolini et al., 1993a, b), but are not useful on a practical basis.

\section{Utilization of pH measurements}

One of the most widely used methods to assess pork quality is muscle $\mathrm{pH}$. Living muscle has a neutral $\mathrm{pH}$ of 7.0 to 7.2. As live muscle converts into meat, $\mathrm{pH}$ drops causing meat to become increasingly acidic. Both the rate of this change and the final $\mathrm{pH}$ are important in determining pork quality. $\mathrm{pH}$ is generally measured within 45 to $60 \mathrm{~min}$ after harvest and/or at $24 \mathrm{~h}$ of harvest (initial $\mathrm{pH}$ and ultimate $\mathrm{pH}$, respectively). Both initial and ultimate $\mathrm{pH}$ measurements can be used to indicate the rate and extent of postmortem glycolysis and generally 
serve as good indicators of meat quality and obviously the time $\mathrm{pH}$ is measured after death can affect $\mathrm{pH}$ values (Scheper, 1971).

Normally, the $\mathrm{pH}$ of muscle drops from 7.2 (physiological) to between 5.5 and 5.8 during the immediate $24 \mathrm{~h}$ post-harvest period. If the $\mathrm{pH}$ declines very rapidly or very slowly or if the ultimate $\mathrm{pH}$ is very high $(>6.1$ to 6.2$)$ or very low $(<5.4)$, the carcass quality characteristics, including water-holding capacity and color, are significantly altered (Bendall and Swatland, 1988). Carcasses with an initial $\mathrm{pH}$ of $<6.2$ are generally classified PSE $24 \mathrm{~h}$ later (Bouton et al., 1971). Utilization of initial $\mathrm{pH}$ as an early detection method allows identification and sorting of carcasses with similar glycolitic rates and allows abattoirs to identify carcasses early postmortem and implement corrective action or sort and distribute them according to their most applicable use. Swatland (1982a) concluded that early postmortem $\mathrm{pH}$ measurements could be used to identify trends in meat quality; however, he did not find the measurements to be a reliable method for sorting carcasses. Similarly, Kauffman et al. (1993) showed that initial pH is not an appropriate predictor of ultimate pork quality for carcasses and demonstrated that ultimate $\mathrm{pH}$ alone is not a reliable indicator of the PSE condition. Wismer-Pedersen (1959) concluded a $\mathrm{pH}$ probe could be inserted into the medial surface of the longissimus of a split carcass, which could identify potential PSE carcasses.

Often, it is of interest to know whether longissimus $\mathrm{pH}$ or color measurements have the potential to predict the $\mathrm{pH}$ or color of other cuts. Many authors (Bendall and Swatland, 1988; Swatland, 1982a, b; Penny et al., 1963; Briskey, 1964; Andrews et al., 2007) have indicated that ultimate $\mathrm{pH}$ measurements can be directly or indirectly related to many important quality attributes, such as color, water-holding capacity, and tenderness. Herring et al. (1971) found final $\mathrm{pH}$ to more accurately predict water-holding capacity and ultimate color scores than initial pH. However, Eikelenboom et al. (1974) showed that initial $\mathrm{pH}$ and ultimate $\mathrm{pH}$ were both related with various quality traits, although ultimate $\mathrm{pH}$ showed a slightly higher relationship than initial $\mathrm{pH}$ when related to $24 \mathrm{~h}$ subjective color readings $(\mathrm{r}=0.6 \mathrm{and} \mathrm{r}=0.5$, respectively).

When investigating aged pork loins, Andrews et al. (2007) found that $\mathrm{pH}$ measurements at $24 \mathrm{~h}$ were useful in predicting final pork color and quality attributes. They found $\mathrm{L}^{*}, \mathrm{~b}^{*}$, percentage purge, and cooking loss linearly decreased with increasing $\mathrm{pH}$. Furthermore, Eikelenboom et al. (1974) concluded that at least one $\mathrm{pH}$ measurement should be used early postmortem when trying to detect potential PSE carcasses. Huff-Lonergan et al. (2002) found 
that the $\mathrm{pH}$ of the semimembranosus was significantly correlated with ultimate $\mathrm{pH}$ measures in the longissimus $(\mathrm{r}=-0.27)$. The magnitude of the correlation was moderate, indicating some predictive value. Hunter $\mathrm{L}^{*}$ values measured at $24 \mathrm{~h}$ postmortem in the semimembranosus were also significantly correlated with the Hunter L* values in the longissimus at 24 and $48 \mathrm{~h}$ postmortem. Again, they found the magnitude of the correlation was moderate, indicating moderate reliability in predicting the color of one muscle based on the color of the other.

In summary, $\mathrm{pH}$ is one of the most widely used methods to assess pork quality and in and sort pork carcasses according to quality. In addition, ultimate $\mathrm{pH}$ measurements can be directly or indirectly related to many important pork-quality attributes such as color, water-holding capacity, and tenderness. Unfortunately, early assessments of $\mathrm{pH}$ are more difficult to do uniformly and may have lower than expected predictive value. Measurement at 24-h postmortem works well, but is not conducive to early quality prediction or control of chilling parameters.

\section{Influence of pH on color}

Muscle pH plays an important role in meat color (Ledward, 1992; Faustman and Cassens, 1990a, b). Ockerman and Cahill (1977) concluded that muscle pH could change the chroma and hue in a desirable direction when elevated and that color could be altered in an undesirable way with the lowering of muscle $\mathrm{pH}$ and the depletion of oxygen. Pork with low $\mathrm{pH}$ is less color stable than normal or higher $\mathrm{pH}$ pork due to increasing rate of myoglobin autoxidation and decreasing rate of metmgyoglobin reduction (Ledward, 1985). In agreement, Zhu and Brewer (1998) concluded that higher $\mathrm{pH}$ meat was the most stable meat condition as it has the highest metmyoglobin reductase activity, while low $\mathrm{pH}$ pork has the lowest metmyoglobin reductase activity and would less stable. Andrews et al. (2007) found that chops from pH 5.6 to 5.9 were the most color stable, and chops with a $\mathrm{pH} \leq 5.5$ had the highest $\mathrm{L}^{*}$ and $\mathrm{b}^{*}$ values and were more susceptible to metmyoglobin formation. Metmyoglobin reductase activity appeared to enhance reduction and retard metmyoglobin formation resulting in slower discoloration at the meat's surface.

Meat with high ultimate $\mathrm{pH}$ has a tighter structure and a greater WHC than normal, lower $\mathrm{pH}$ meat. This tight structure decreases the rate of oxygen diffusion and subsequent pigment oxygenation, and consequently reduces the amount of light reflected from the meat surface (Lawrie, 1958a, b; MacDougall and Rhodes, 1972). Bendall and Swatland (1988) postulated a 
low $\mathrm{pH}$ would increase the light scattering by increasing the angular deflection of light passing through the myofibrils. Swatland (1989) measured individual muscle fibers and showed that the optical path difference tends to increase when $\mathrm{pH}$ is decreased because myofibrils are strongly birefringent. Reflection, refraction, and scattering may all be involved in the inverse relationship between meat $\mathrm{pH}$ and paleness. Microscopically, muscle fibers are birefringent. Birefringence is strong in $\mathrm{A}$ bands and $\mathrm{Z}$ lines, but much weaker in I bands, and optical path differences between the two refractive indices increase as $\mathrm{pH}$ decreases (Swatland, 1989).

Gotoh and Sikama (1974) showed the half-life of oxymyoglobin at $0^{\circ} \mathrm{C}$ was 5 days at a $\mathrm{pH}$ of 5.0 and 1 year at a $\mathrm{pH}$ of 9.0, indicating that oxymyoglobin denatures more quickly at lower $\mathrm{pH}$. A low $\mathrm{pH}$ environment accelerates the promotion of bound oxygen and favors the release of superoxide anions (Livingston and Brown, 1981). Members and Satterlee (1975) reported myoglobin of PSE pork to autoxidize at a rate 1.5-2 times as fast as in normal pork.

Myoglobin in pork is particularly vulnerable to acid denaturation (Satterlee and Zachariah, 1972), but paleness from protein denaturation is probably superimposed on a biophysical relationship between paleness and $\mathrm{pH}$ extending over a wide $\mathrm{pH}$ range. The myofilament lattice shrinks towards the isoelectric point of its proteins, thus increasing the refractive difference between myofibrils and sarcoplasm. Hamm (1960) and Offer et al. (1989) proposed this increases reflection at the myofibrillar surface reflection remains a possible contributor to the inverse relationship between $\mathrm{pH}$ and paleness, although it has not yet been measured or proven. The results of Swatland (2002) support the relationship between paleness and refraction. Light is refracted as it passes through meat. The original directionality of the light may be maintained farther if refraction is weak, allowing incident light to pass deep into the meat where it is absorbed. When refraction is strong, the original directionality may soon be lost, more light is returned to the meat surface, and it appears pale in color.

Increased antemortem glycolysis induced either by excitation, fasting, or cold stress prior to harvest will result in high muscle $\mathrm{pH}$ and ultimately poor meat quality (Lawrie, 1991). Swatland (1989) suggested the possibility that $\mathrm{pH}$ measurements be used to predict pork color after storage. Roserio et al. (1994) found that as muscle ultimate $\mathrm{pH}$ increased, lightness decreased and redness and yellowness increased. Correlations between ultimate $\mathrm{pH}$ and $\mathrm{CIE} \mathrm{L}^{*}$ and $\mathrm{a}^{*}$ values were fair $(\mathrm{r}=-0.42$ and $\mathrm{r}=0.32$, respectively). A similar finding was reported by Swatland (1982a) who used 45 -min $\mathrm{pH}$ on the right longissimus to predict paleness at $5 \mathrm{~d}$ 
postmortem on the left longissimus. He later concluded $\mathrm{pH}$ was a good measurement to identify trends in color, but found it was not reliable for carcass sorting. However, in another experiment, $\mathrm{pH}$ was taken $1.5 \mathrm{~h}$ and 24-h postmortem and was strongly related $(\mathrm{r}=-0.81$ and $\mathrm{r}=$ -0.71 , respectively) to the brightness of longissimus chops 24-h postmortem (Swatland, 1982b). Andrews et al. (2007) found that 24-h pH measurements could be used to predict color as well as other quality characteristics of pork loins aged $45 \mathrm{~d}$ postmortem.

In summary, muscle $\mathrm{pH}$ plays a very important role in meat color. Chops from $\mathrm{pH} 5.6$ to 5.9 have been found to be the most color stable and chops with a $\mathrm{pH} \leq 5.5$ have been found to have the highest $\mathrm{L}^{*}$ and $\mathrm{b}^{*}$ values. Meat with high ultimate $\mathrm{pH}$ has a tighter structure and a greater WHC than normal, lower $\mathrm{pH}$ meat, and will be darker in color. 24-h pH measurements can be used to predict color as well as other quality characteristics of pork loins.

\section{Influence of $\mathrm{pH}$ on water-holding capacity}

Many authors have outlined methods (Wierbicki and Deatherage, 1958; Kauffman et al., 1969; Monin et al., 1981; Reuter, 1982) used to measure WHC with varying degrees of success. van Laack et al. (1994) reported that ultimate $\mathrm{pH}$ accounted for only $24 \%$ of the variation in WHC, however, Joo et al. (1995) showed that ultimate $\mathrm{pH}$ accounted for $67 \%$ of the variation in WHC and was highly related to percentage drip loss. Herring et al. (1971) concluded ultimate $\mathrm{pH}$ was the most important factor in predicting WHC in pork loins. Furthermore, Hamm (1986) stated water-binding myofibrillar proteins are potentially denatured during a low $\mathrm{pH}$, high temperature condition, consequently binding less water. Similarly, Offer and Trinick (1983) added a series of $0.1 \mathrm{M} \mathrm{NaCl}$ solutions buffered with various $\mathrm{pH}$ ranges and found that as $\mathrm{pH}$ increased from 7 to 9 , the myofibrils swelled by $15 \%$ in diameter. In addition, they repeated this procedure, reducing the $\mathrm{pH}$ from 7 to 5 and found the myofibrils shrank $15 \%$ in diameter. This shrinkage may be caused by the drop in the intracellular $\mathrm{pH}$ due to the accumulation of lactic acid.

Thomsen and Zeuthen (1988) stated that the WHC of meat is at a minimum at a pH of 5.0, which corresponds to the isoelectric point of actomyosin. At the isoelectric point, the net charge of a protein is at its minimum (the protein has the maximum amount of intermolecular salt linkages between positively and negatively charged particles). With $\mathrm{pH}$ levels above the isoelectric point of meat $(>6.0)$, the number of available charges is enhanced and improves the 
WHC of the meat. As the $\mathrm{pH}$ of muscle increases, WHC also increases at a constant rate up to three times the normal retention in living muscle (Kauffman et al., 1986).

Hamm (1960) showed that the change in WHC of muscle homogenates was closely related to $\mathrm{pH}$. Furthermore, Bouton et al. (1972) stated that a linear relationship between meat $\mathrm{pH}$ and the amount of expressed juice was apparent in ovine muscles. In a $\mathrm{pH}$ range of 5.0 to 6.5, a change in $\mathrm{pH}$ has a dramatic effect on WHC due to the changes in the state of ionization of histidine and to a lesser extent of glutamic acid residues.

In summary, a low $\mathrm{pH}$ denatures myofibrillar proteins and consequently, they bind less water. The WHC of meat is lowest at a $\mathrm{pH}$ of 5.0 (isoelectric point of actomyosin) and highest at $\mathrm{pH}$ levels $>6.0$ (isoelectric point of meat). Therefore, $\mathrm{pH}$ measurements have been used in order to predict the WHC of meat.

\section{Relationship of water-holding capacity and color}

Muscle color has been related to water-holding capacity in pork (Wismer-Pederson, 1959; Borggaard et al., 1989). van Laack et al. (1994) found a correlation of $r=0.37$, which indicates that the variation in WHC (measured as \% drip) could be explained by color ( $\mathrm{L}^{*}$ value). CIE L* explained $58 \%$ of the variation in WHC measured by the filter paper wetness method. By removing samples classified as DFD, an inflection point was observed at a drip loss of $6 \%$ and an $L^{*}$ value of 59 (van Laack et al., 1994). Offer (1991) suggested that the relationship between WHC and color could be explained by the knowledge of the onset of rigor and the denaturation of the protein myosin. Color lightness is influenced by the denaturation of myofibrillar and sarcoplasmic proteins, which occur while the temperature is high and $\mathrm{pH}$ is low (van Laack et al., 1994).

In summary, several researchers have found water-holding capacity to be related to muscle color in pork (Wismer-Pederson, 1959; Borggaard et al., 1989) and van Laack et al. (1994) found $\mathrm{L}^{*}$ to be predictive of WHC.

\section{Japanese color score correlations}

Analysis of data, including various pork carcass characteristics, must be completed to create a prediction equation that could be used to effectively sort pork carcasses according to JCS for valuable export markets. Previous research (Van Oeckel et al., 1999) has found that subjective JCS evaluation was best correlated with the instrumental CIE L* $(r=0.82)$. Japanese 
color scores were only slightly better correlated with hue than with CIE $b^{*}$ and $a^{*}$. No significant correlation was found between JCS and chroma. Hue was highly correlated with CIE $\mathrm{a}^{*}$. Likewise, chroma and CIE $\mathrm{b}^{*}$ were highly correlated $(\mathrm{r}=0.88)$. For all measurements, normal pork meat was more accurately classified than PSE meat.

Huff-Lonergan et al. (2002) measured carcass composition traits, $\mathrm{pH}$ measurements and subjective quality scores at $24 \mathrm{~h}$ postmortem and at $48 \mathrm{~h}$ postmortem, measuring $\mathrm{pH}$, Hunter $\mathrm{L}^{*}$ values, drip loss, glycolytic potential, ratio of type IIa/IIb fibers, myosin heavy chains (IIa/IIb), total lipids, instrumental measures of tenderness, cooking loss measurements, and sensory evaluations. They found significant correlations between many carcass, instrumental, biochemical measurements, as well as sensory traits. In addition, they found subjective color, marbling, and firmness scores were all significantly correlated with all sensory traits except juiciness. Subjective color was also significantly correlated with firmness, drip loss, and instrumental evaluation of tenderness (Star probe). These data indicate that darker product had a greater tendency to be firmer, have less drip loss, and be more tender. Although the correlation between subjective color and flavor was significant, the magnitude of the correlation was small enough to indicate that other factors may have a greater influence on flavor.

Huff-Lonergan et al. (2002) took pH measurements at both 24 and $48 \mathrm{~h}$ postmortem and found the correlation between these two measurements to be significant $(r=0.71)$. Correlations of $\mathrm{pH}$ measured at 24 or $48 \mathrm{~h}$ postmortem with other quality measurements were very similar; significant correlations were found between both $24-$ and $48-\mathrm{h} \mathrm{pH}$ measurements in addition to many of the quality traits measured. Traits that were most highly correlated with 24- and 48-h pH measurements were: color, drip loss, tenderness (both Star Probe and sensory tenderness), flavor and off-flavor scores, and cooking loss. These results indicate that a lower ultimate $\mathrm{pH}$ of the product is associated with lighter-colored product, product with higher drip loss, less tender product, and product with more off-flavor, but less pork flavor.

In addition, Huff-Lonergan et al. (2002) found subjective color to be significantly correlated with Hunter $L^{*}$ values $(r=-0.69)$, indicating that Hunter $L^{*}$ values were predictive of subjective color scores. Post rigor $\mathrm{pH}$ measures (at both 24 and $48 \mathrm{~h}$ ) were among the traits measured that had the highest correlations to both subjective color scores and Hunter L* values. Additionally, traits that were closely related to ultimate $\mathrm{pH}$ (glycolytic potential and lactate concentration) were also among the traits that were significantly correlated with color 
measurements. Binder et al. (2004) concluded that the ultimate $\mathrm{pH}$ of the longissimus thoracis could explain $79 \%$ of the variation in subjective color, which increased as $\mathrm{pH}$ increased. Similar results were found by Homm et al. (2006) who found anterior chops were darker and had higher $\mathrm{pH}$. Several other researchers have found that products with a higher color score tended to have a higher post-rigor pH (Huff-Lonergan et al., 2002; DeVol et al., 1988; Hovenier et al., 1993).

Van Oeckel et al. (1999) studied the extent to which instrumental color determinations were related to Japanese color scores. Of the instrumental color determinations, they found CIE $L^{*}(r=-0.82)$ was highly correlated to Japanese color score. In addition, they found that Japanese color scores could be predicted by $\mathrm{pH}$ with determination coefficients between 15 and $28 \%$. Using the Japanese color standards to establish a range, the instrumental measure most often and most highly correlated with visual pink color intensity (full $\mathrm{pH}$ range), regardless of muscle and instrument/illuminant, was $\mathrm{L}^{*}$ value (Brewer et al., 2001). They also found the second best measure was hue angle. Large differences in "yellowness" (+ $b^{*}$ value) measured instrumentally may have a great deal of impact when these measures (and those measured which are calculated using $b^{*}$ value, such as hue angle and chroma) are related back to visual color. Brewer et al. (2001) found L* value was unaffected by bloom time, and was moderately correlated with $\mathrm{pH}$ and visual pink color of longissimus thorasic, making it the best overall indicator of both PSE and DFD conditions.

In summary, casual relationships have been observed between key indicators of pork quality, although some do not seem directly interrelated. Despite this, many investigators have found instrumental $\mathrm{L}^{*}$ values to be highly correlated with JCS. Others have found that traits which were closely related to ultimate $\mathrm{pH}$ measurements were among the traits that were significantly correlated with objective and/or subjective color measurements. One study found JCS were only slightly better correlated with hue angle than with CIE $b^{*}$ and $a^{*}$; no significant correlations found between JCS and chroma. Based upon the reviewed research, instrumental color and $\mathrm{pH}$ measurements have been found to accurately predict JCS and they should to be used when developing a prediction equation. 


\section{CONSUMER PREFERENCES}

Across numerous countries (Australia, Brazil, France, Germany, Ireland, Italy, Korea, Poland, Spain, Sweden, Twain, and the United Kingdom), consumer studies have found color to be the single most important criteria for pork selection (Cipolli et al., 2003; Cho et al., 2007; Ngapo et al., 2004; Glitsch, 2000). Cho et al. (2007) found Korean consumers' preference for pork color varied by region. In their study, they found that only slightly more Korean consumers chose dark red-colored pork chops over light-colored pork chops when making a purchasing decision. Similar results were found by Ngapo et al. (2004) who found French consumers (35\%) also preferred to purchase dark red-colored pork chops over light-colored pork chops (25\%). However, very few consumers base their purchasing decisions on color alone. Although Asian consumers prefer dark-red pork, that is not the case with consumers world-wide. Australian, Irish and Polish consumers showed the strongest preference for the light-red pork while Taiwanese consumers showed strong preference for dark red pork (Ngapo et al., 2007).

In both studies by Ngapo et al. (2004) and Cho et al. (2007), they found other characteristics which influenced consumers' pork purchases were marbling, drip, and leanness of the chop. Ngapo et al. (2007) found that only $23 \%$ of the consumers chose which pork chop to purchase using a single characteristic. Consumers most often (41\%) used two of the four varied characteristics to make their choice when purchasing pork chops, while $31 \%$ used at least three.

In a study of U.S. consumers, Romans and Norton (1989) found that when purchasing pork chops, a majority of U.S. consumers cited leanness was more influential than color. Dublin, Ireland consumers ranked leanness as the most important selection criteria among six porkquality characteristics (O’Mahony et al., 1995). Presentation of the chop ranked first, color ranked third, while drip ranked sixth.

In summary, cultural differences exist amongst pork consumers for pork appearance characteristics. With the increased rate in worldwide pork consumption, it is important for producers to understand the cultural differences in order to remain at the forefront of the competition for potential markets (Verbeke, 2000; Jaeger et al., 1998). Although many consumers cite color is the most important factor they consider when purchasing pork, their preference for pork color differs. Effective marketing should respond to differences in consumer preferences and pork processing plants should strive to sort pork accordingly. 


\section{Literature cited}

Apple, J. K., C. V. Maxwell, B. deRodas, H. B. Watson, and Z. B. Johnson. 2000. Effect of magnesium mica on performance and carcass quality of growing-finishing swine. J. Anim. Sci. 78:2315-2143.

Apple, J. K., W. J. Roberts, C. V. Maxwell, C. B. Boger, T. M. Fakler, K. G. Friesen, and Z. B. Johnson. 2004. Effect of supplemental manganese on performance and carcass characteristics of growing-finishing swine. J. Anim. Sci. 82:3267-3276.

Andrews, B. S., S. Hutchison, J. A. Unruh, M. C. Hunt, J. E. Boyer JR, and R. C. Johnson. 2007. Influence of $\mathrm{pH}$ at $24 \mathrm{~h}$ postmortem on quality characteristics of pork loins aged 45 days postmortem. J. Muscle Foods. 18:401-419.

Bate-Smith, E. C., and J. R. Bendall. 1949. Factors determining the time course of rigor mortis. J. Physiol. 110:47-65.

Becker, B. A., H. F. Mayes, G. L. Hahn, J. A. Nienaber, G. W. Jesse, M. E. Anderson, H. Heymann, and H. B. Hedrick. 1989. Effect of fasting and transport on various physiological parameters and meat quality of slaughter hogs. J. Anim. Sci. 67:334-341.

Beecher, G. R., R. G. Cassens, W. G. Hoekstra, and E. J. Briskey. 1965. Red and white fiber content and associated post-mortem properties of seven porcine muscles. J. Food Sci. 30:969-976.

Bendall, J. R. 1973. Postmortem changes in muscle. In The structure and Function of Muscle, 2nd ed. G. M. Bourne, ed. Academic Press, NY.

Bendall, J. R., and H. J. Swatland. 1988. A review of the relationships of $\mathrm{pH}$ with physical aspects of pork quality. Meat Sci. 24:85-126.

Bendall, J. R., and J. Wismer-Pedersen. 1962. Some properties of the fibrillar proteins of normal and watery pork muscle. J. Food Sci. 27:144-157.

Binder, B. S., E. Ellis, M. S. Brewer, D. Campion, E. R. Wilson, and F. K. McKeith. 2004. Effect of ultimate $\mathrm{pH}$ on the quality characteristics of pork. J. Muscle Foods. 15:139-154.

Borchert, L. L., and E. J. Briskey. 1964. Prevention of pale soft exudative pork muscle through partial freezing with liquid nitrogen post mortem. J. Food Sci. 29:203-209. 
Borggaard, C., J. P. Anderson, and P. Barton-Gade. 1989. Further development of the MQMequipment for measuring water-holding capacity and intramuscular fat on-line. Pages 212-219 in Proc. 35th Int. Congr. Meat Sci. Technol., Copenhagan, Denmark.

Bouton, P. E., R. D. Carroll, P. V. Harris, and W. R. Shorthose. 1973. Influence of pH and fiber contraction state upon factors affecting tenderness of bovine muscles. J. Food Sci. 38:404-407.

Bouton, P. E., P. V. Harris, and W. R. Shorthose. 1971. The effect of $\mathrm{pH}$ upon the water-holding capacity and tenderness of mutton. J. Food Sci. 36:435-439.

Bouton, P. E., P. V. Harris, and W. R. Shorthose. 1972. The effects of ultimate pH on ovine muscle: mechanical properties. J. Food Sci. 37:356-360.

Brewer, M. S., A. Sosnicki, B. Field, R. Hankes, K. J. Ryan, L. G. Zhu, and F. K. McKeith. 2004. Enhancement effects on quality characteristics of pork derived from pigs of various commercial genetic backgrounds. J. Food Sci. 69:SNQ5-SNQ10.

Brewer, M. S., L. G. Zhu, and F. K. McKeith. 2001. Marbling effects on quality characteristics of pork loin chops; consumer purchase intent, visual and sensory characteristics. Meat Sci. 59:153-163.

Briskey, E. J. 1964. Etiological status and associated studies of pale, soft, exudative porcine musculature. Adv. Food Res. 13:89-168.

Briskey, E. J., and J. Wismer-Pedersen. 1961. Biochemistry of pork muscle structure. I. Rate of anaerobic glycolysis and temperature changes versus the apparent structure of muscle tissue. J. Food Sci. 26:297-305.

Cassens, R. G., R. G. Kauffman, A. Scherer, and D. L. Meeker. 1992. Variations in pork quality: a 1991 U.S.A. survey. Pages 237-240 in 38th Int. Congr. Meat Sci. Technol., ClermontFerrand, France.

Channon, H. A., A. M. Payne, and R. D. Warner. 2000. Halothane genotype, pre-slaughter handling and stunning method all influence pork quality. Meat Sci. 57:359-363.

Chizzolini, R., E. Noveli, A. Badiani, P. Rosa, and G. Delbono. 1993a. Objective measurements of pork quality: Evaluation of various techniques. Meat Sci. 34:49-77.

Chizzolini, R., E. Noveli, A. Badiani, G. Delbono, and P. Rosa. 1993b. Objective measurements of pork quality: Evaluation of on-line techniques. Meat Sci. 34:79-93. 
Cho, S., B. Park, T. Ngapo, J. Kim, E. Dransfield, I. Hwang, and J. Lee. 2007. Effect of meat appearance on South Korean consumers' choice of pork chops determined by image methodology. J. of Sensory Studies. 22:99-114.

Cipolli, K. M.V. A., E. T. Silveira, T. M. Ngapo, and E. Dransfield. 2003. Consumer preferences of pork chops - the Brazilian study. Abstract. Page 187 in $5^{\text {th }}$ Pangborn sensory science symposium, Boston, U.S.A.

DeSmet, S. M., H. Pauwels, S. De Bie, D. I. Deymeyer, J. Callewier, and W. Eeckhout. 1996. Effect of halothane genotype, breed, feed withdrawal, and lairage on pork quality of Belgian slaughter pigs. J. Anim. Sci. 74:1854-1863.

DeVol, D. L., F. K. McKeith, P. J. Bechtel, J. Novakofski, R. D. Shanks, and T. R. Carr. 1988. Variation in composition and palatability traits and relationships between muscle characteristics and palatability in a random sample of pork carcasses. J. Anim. Sci. 66:385-395.

Edwards, D. B., R. O. Bates, and W. N. Osburn. 2003. Evaluation of Duroc- vs. Pietrain-sired pigs for carcass and meat quality measures. J. Anim. Sci. 81:1895-1899.

Eggert, J. M., F. F. Depreux, A. P. Schinckel, A. L. Grant, and D. E. Gerrard. 2002. Myosin heavy chain isoforms account for variation in pork quality. Meat Sci. 61:117-126.

Eikelenboom, G., A. H. Bolink, and W. Sybesma. 1991. Effects of feed withdrawl before delivery on pork quality and carcass yield. Meat Sci. 29:25-30.

Eikelenboom, G., D. R. Campion, R. G. Kauffman, and R. G. Cassens. 1974. Early postmortem methods of detecting ultimate porcine muscle quality. J. Anim. Sci. 39:303-308.

Eikelenboom, G., and L. Nanni Costa. 1988. Fiber optic measurements in Landrace pigs of different halothane phenotypes. Meat Sci. 23:9-19.

Ellis, M., F. K. McKeith, and K. D. Miller. 1999. The effects of genetic and nutritional factors on pork quality-A Review. Asian-Australian J. Anim. Sci. 12:261-270.

Estrade, M., X. Vignon, and G. Monin. 1993. Effects of the RN- gene on ultrastructure and protein fractions in pig muscle. Meat Sci. 35: 313-319.

Fabrega, E., X. Manteca, J. Font, M. Gispert, D. Carrion, A. Velarde, J. L. Ruiz-de-la-Torre, and A. Diestre. 2002. Effects of halothane gene and pre-slaughter treatment on meat quality and welfare from two pig crosses. Meat Sci. 62:463-475. 
Faustman, C., and R. G. Cassens. 1990a. Influence of aerobic metmyoglobin reducing capacity on color stability of beef. J. Food Sci. 55:1278-1283.

Faustman, C., and R. G. Cassens. 1990b. The biochemical basis for discoloration in fresh meat: a review. J. Muscle Foods. 1:217-243.

Fernandez, X., E. Neyraud, T. Astruc, and V. Sante. 2002. Effects of halothane genotype and pre-slaughter treatment on pig meat quality. Part 1: Postmortem metabolism, meat quality indicators and sensory traits of m. Longissimus lumborum. Meat Sci. 62:429-437.

Fernandez, X., and E. Tornberg. 1991. A review of the causes of variation in muscle glycogen content and ultimate $\mathrm{pH}$ in pigs. J. Muscle Foods. 2:209-235.

Feldhusen, F., and M. Kühne. 1992. Effects of ultra rapid chilling and on length of sarcomeres, and tenderness of pork. Meat Sci. 32:161-171.

Fisher, P., F. D. Mellett, and L. C. Hoffman. 2000. Halothane genotype and pork quality. 1. Carcass and meat quality characteristics of three halothane genotypes. Meat Sci. 54:97105.

Fjelkner-Modig, S., and H. Rudérus. 1983. The influence of exhaustion and electrical stimulation on meat quality of young bulls: Part 2-Physical and sensory properties. Meat Sci. 8:203202.

Follett, M. J., G. A. Norman, and P. W. Ratcliff. 1974. The ante-rigor excision and air cooling of beef semimembranosus muscles at temperatures between $-5^{\circ} \mathrm{C}$ and $+15^{\circ} \mathrm{C}$. J. Food Tech. 9:509-523.

Frederick, B. R., E. van Heugten, and M. T. See. 2004. Timing of magnesium supplementation administered through drinking water to improve fresh and stored pork quality. J. Anim. Sci. 82:1454-1460.

Gentry, J. G., J. J. McGlone, M. F. Miller, and J. R. Blanton. 2004. Environmental effects on pig performance, meat quality, and muscle characteristics. J. Anim. Sci. 82:209-217.

Glitsch, K. 2000. Consumer perceptions of fresh meat quality: cross-national comparison. British Food Journal. 103:177-194.

Gotoh, T., and K. Sikama. 1974. Autoxidation of oxymyoglobin from bovine heart muscle. Arch. Biochem. Biophys. 163:476-481.

Grandin, T. 1999. Handling pigs for optimum performance on the farm and in the slaughter plant. Colorado State Univ. Environment and Behavior-Anim. Sci. Available: 
http://ansci.colostate.edu/res/environ/handle_pigs_performance.html. Accessed March $18,2007$.

Grandin, T. 2000. The principles of low stress restraint for pigs. Colorado State Univ. Department of Anim. Sci. Available: http://ansci.colostate.edu/ran/meat/pigs/rest_princ2.html. Accessed March 18, 2007.

Greenleaf, J., K. E. Olsson, and B. Saltin. 1969. Muscle glycogen content and its significance for water content of body. Acta Physiol. Scand. S:86. (Abstr.)

Hamilton, D. N., M. Ellis, M. D. Hermann, F. K. McKeith, K. D. Miller, and K. W. Purser. 2002. The impact of Longissimus glycolytic potential and short-term feeding of magnesium sulfate heptahydrate prior to slaughter on carcass characteristics and pork quality. J. Anim. Sci. 80:1586-1592.

Hamilton, D. N., K. D. Miller, M. Ellis, F. K. McKeith, and E. R. Wilson. 2003. Relationships between longissimus glycolytic potential and swine growth performance, carcass traits, and pork quality. J. Anim. Sci. 81:2206-2212.

Hamm, R. 1960. Biochemistry of meat hydration. Adv. Food Res. 10:355-463.

Hamm, R. 1986. Current problems in meat research. Fleischwirtschaft. 66:1772-1776.

Hamm, R., and F. E. Deatherage. 1960. Influence of freezing and thawing and freeze dehydration on the hydration and charges of meat proteins. Food Technol. 14:B41.

Hedrick, H. B., E. D. Aberle, J. C. Forest, M. D. Judge, and R. A. Merkel. 1994. Pages 55-268 in Principles of Meat Science, 3rd ed.

Herring, H. K., J. H. Haggard, and L. J. Hansen. 1971. Studies on chemical and physical properties of pork in relation to quality. J. Anim. Sci. 33:578-586.

Homm, J. W., A. T. Waylan, J. A. Unruh, and R. C. Johnson. 2006. Influence of chop location within a loin on boneless pork longissimus quality. J. Muscle Foods. 17:221-236.

Honikel, K. O. 1987. Pages 273-284 in The influence of chilling on meat quality attributes of fast glycolysing pork muscle. In P. V. Tarrent, G. Eikelenboom, and G. Monin, ed., Evaluation and Control of Meat Quality in Pigs. Martinus Nijhoff Publishers, Kluwer Academic Publishers, Hingham, MA.

Hovenier, R., E. W. Brascamp, E. Kanis, J. H. J. Van der Werf, and A. P. A. M. Wassenberg. 1993. Economic values of optimum traits: the example of meat quality in pigs. J. Anim. Sci. 71:1429-1433. 
Huff-Lonergan, E., T. J. Baas, M. Malek, J. C. M. Dekkers, K. Prusa, and M. F. Rothschild. 2002. Correlations among selected pork quality traits. J. Anim. Sci. 80:617-627.

Jaeger, S. R., Z. Andani, I. N. Wakeling, and H. J. H. MacFie. 1998. Consumer preferences for fresh and aged apples: A cross-cultural comparison. Food Quality and Preference. 9:355366.

Jakobsson, B., and N. Bengtsson. 1973. Freezing of raw beef-influence of aging, freezing rate and cooking method on quality and yield. J. Food Sci. 38:560-565.

Jeremiah, L. E., A. K. Tong, and L. L. Gibson. 1991. The usefulness of muscle color and pH for segregating beef carcasses into tenderness groups. Meat Sci. 30:97-114.

Jones, S. D. M., R. E. Rempala, and C. R. Haworth. 1985. Effects of water restriction on carcass shrink and pork quality. Can. J. Anim. Sci. 65:613-618.

Joo, S., R. G. Kauffman, B. Kim, and C. Kim. 1995. The relationship between color and waterholding capacity in postrigor porcine longissimus muscle. J. Muscle Foods. 6:211-226.

Juncher, D., B. Ronn, E. T. Mortensen, P. Henckel, A. Karlsson, and L. H. Skibsted. 2001. Effect of pre-slaughter physiological conditions on the oxidative stability of colour and lipid during chill storage of pork. Meat Sci. 58:347-357.

Kauffman, R. G., B. C. Beidenstein, D. Garrigan, and Q. E. Kolb. 1969. Meat Quality Circular 1007. Coop. Ext. Sv., Coll. Agr., Univ. of Illinois, Urbana, IL.

Kauffman, R. G., W. Sybesma, F. J. M. Smulders, G. Eikelenboom, B. Engle, R. L. J. M. van Laack, A. H. Hoving-Bolink, P. Sterrenburg, E. V. Nordheim, P. Walstra, and P. G. van der Wal. 1993. The effectiveness of examining early post-mortem musculature to predict ultimate pork quality. Meat Sci. 34:283-300.

Kauffman, R. G., and M. Zaar. 1986. The use of filter paper to estimate drip loss of porcine musculature. Meat Sci. 18:191-200.

Kropf, D. H. 1980. Effects of retail display conditions on meat color. Pages 15-32 in Proc. 32nd Recip. Meat Conf.

Kropf, D. H. 1993. Color Stability. Meat Focus Intl. 2:269-275.

Kuchenmeister, U., G. Kuhn, and E. Ender. 2000. Seasonal effects on $\mathrm{Ca}+2$ transport of sarcoplasmic reticulum and on meat quality of pigs with different malignant hyperthermia status. Meat Sci. 55:239-245. 
Lawrie, R. A. 1958a. Physiological stress in relation to dark-cutting beef. J. Sci. Food Agric. 9:721.

Lawrie, R. A. 1958b. Abnormally low ultimate pH in pig muscle. Nature. 182:807-810.

Lawrie, R. A. 1991. Meat Science, 5th ed., Pergamon Press, Oxford.

Ledward, D. A. 1985. Post-slaughter influences on the formation of metmyoglobin in beef muscles. Meat Sci. 15:149-171.

Ledward, D. A. 1992. Colour of raw and cooked meat. Pages 128-144 in The Chemistry of Muscle-based foods. Ledward, D. A., D. E. Johnston, and M. Knight, eds. Royal Society of Chemistry, London, England.

LeRoy, P., J. Naveau, and J. M. Elsen. 1989. Evidence for a new major gene influencing meat quality in pigs. Pages 3-9 in Proc. 40th EAAP Ann. Meet., Dublin, Ireland.

Livingston, D. J., and W. D. Brown. 1981. The chemistry of myoglobin and its reactions. Food Technol. 35:244-252.

Lundstrom, K., A. Andersson, and I. Hansson. 1996. Effects of the RN gene on technological and sensory meat quality in crossbred pigs with Hampshire as terminal sire. Meat Sci. 42:145-153.

Lundstrom, K., I. Hansson, and G. Bjarstorp. 1987. Meat quality in boars and gilts after immediate slaughter or lairage of two hours. Page 191 in Evaluation and control of Meat Quality in Pigs. P. V. Tarrant, G. Eikelenboom and G. Monin, eds. Martinus Nijhoff, Dordrecht.

MacDougall, D. B. 1982. Changes in the color and opacity of meat. Food Chem. 9:75-88.

MacDougall, D. B., and D. N. Rhodes. 1972. Characteristics of the appearance of meat. III. Studies on the color or meat from young bulls. J. Sci. Food Agric. 23:637-643.

Martino, M. N., L. Otero, P. D., Sanz, and N. E. Zartizky. 1998. Size and location of ice crystals in pork frozen by high-pressure-assisted freezing as compared to classical methods. Meat Sci. 50:303-313.

Meadus, W. J., and R. MacInnis. 2000. Testing for the RN- gene in retail pork chops. Meat Sci. 45:231-237.

Members, M., and L. D. Satterlee. 1975. Physico-chemical characterization of normal and PSE porcine muscle myoglobins. J. Food Sci. 40:40. 
Moelich, E., L. C. Hoffman, and P. J. Conradie. 2003. Sensory and functional meat quality characteristics of pork derived from three halothane genotypes. Meat Sci. 63:333-338.

Moeller, S. J., T. J. Baas, T. D. Leeds, R. S. Emnett, and K. M. Irvin. 2003. Rendement Napole gene effects and a comparison of glycolytic potential and DNA genotyping for classification of Rendement Napole status in Hampshire-sired pigs. J. Anim. Sci. 81:402410.

Monin, G., and P. Sellier. 1985. Pork of low technological quality with a normal rate of muscle $\mathrm{pH}$ fall in the intermediate postmortem period: The case of the Hampshire breed. Meat Sci. 13:49-63.

Monin, G., P. Sellier, L. Ollivier, R. Goutefongea, and J. P. Girard. 1981. Carcass characteristics and meat quality of halothane negative and halothane positive pietrain pigs. Meat Sci. 5:413-423.

Monin, G., A. Talmant, D. Laborde, and M. Zabari. 1986. Compositional and enzymatic characteristics of the longissimus dorsi muscle from Large White, Halothane-Positive and Halothane-Negative Pietrain, and Hampshire pigs. Meat Sci. 16:307-316.

Murray, A. C., S. D. M. Jones, and A. P. Sather. 1989. The effects of pre-slaughter feed restriction and genotype for stress susceptibility on pork lean quality and composition. Can. J. Anim. Sci. 69:83-91.

Nakai, H., F. Saito, T. Ikeda, S. Ando, and A. Komatsu. 1975. Standard models of pork-colour. Pages 69-74 in Bull. No. 29 Nat. Inst. Animal Indust., Chiba, Japan.

Ngapo, T. M., I. H. Babare, J. Reynolds, and R. F. Mawson. 1999a. Freezing and thawing effect on drip loss from samples of pork. Meat Sci. 53:149-158.

Ngapo, T. M., I. H. Babare, J. Reynolds, and R. F. Mawson. 1999b. Freezing rate and frozen storage effects on the ultrastructure of samples of pork. Meat Sci. 53:159-168.

Ngapo, T. M., I. H. Babare, J. Reynolds, and R. F. Mawson. 1999c. A preliminary investigation of the effects of frozen storage on samples of pork. Meat Sci. 53:169-177.

Ngapo, T. M., J. F. Martin, and E. Dransfield. 2004. Consumer choices of pork chops: Results from three consumer panels in France. Food Qual. Preference. 15:349-359.

Ngapo, T. M., J. F. Martin, and E. Dransfield. 2007. International preferences for pork appearance: I. Consumer choices. Food Qual. Preference. 18:26-36. 
NPPC. 1999. Procedures to evaluate market hogs. National Pork Producers Council, Des Moines, IA.

Ockerman, H. W., and V. R. Cahill. 1977. Microbiological growth and pH effects on bovine tissue inoculated with Pseudomonas putrefaciens, Bacillus subtilis or Leuconostoc mesenteroides. J. Food Sci. 42:141-145.

Ockerman, H. W., H. B. Craig, and T. N. Blumer. 1964. Volatile chemical compounds in drycured hams. J. Food Sci. 29:123-129.

Offer, G., and P. Knight. 1991. The structural basis of water-holding in meat part 2: drip losses. Pages 173-243 in Development in meat science. R. Lawrie, ed. Elsevier Applied Science, London, England.

Offer, G., P. Knight, R. Jeacocke, R. Almond, T. Cousins, J. Elsey, N. Parsons, A. Sharp, R. Starr, and P. Purslow. 1989. The structural basis of the water-holding, appearance and toughness of meat and meat properties. Food Microstructure. 8:151-170.

Offer, G., and J. Trinick. 1983. On the mechanism of water-holding in meat: The swelling and shrinking of myofibrils. Meat Sci. 8:245-281.

O’Keefe, M., and D. E. Hood. 1980. Anoxic storage of fresh beef. 2: Colour stability and weight loss. Meat Sci. 5:267-281.

O’Mahony, R., C. Cowan, and M. Keane. 1991. Dublin consumers and pork: attributes to quality. British Food Journal. 97:26-33.

O’Neill D. J., P. B. Lynch, D. J. Troy, D. J. Buckley, and J. P. Kerry. 2003. Influence of the time of year on the incidence of PSE and DFD in Irish pig meat. Meat Sci. 64:105-111.

Penny, I. F., C. A. Voyle, and R. A. Lawrie. 1963. The comparison of freeze-dried beef muscle of high and low ultimate pH. J. Sci. Food Agric. 14:53.

Peter, J. B., C. A. Gillespi, R. J. Barnard, K. E. Stempel, and V. R. Edgerton. 1972. Metabolic profiles of 3 fiber types of skeletal muscle in guinea-pigs and rabbits. Biochemistry. 11:2627-2633.

Rae, W. A., and M. A. Price. 1986. The homogeneity of $\mathrm{pH}$ and color of muscles in dark cutting carcasses. Can. J. Anim. Sci. 66:1170.

Renerre, M. 1990. Review: Factors involved in the discoloration of beef. J. Food Sci. 25:613630. 
Renerre, M., and R. Labas. 1987. Biochemical factors influencing metmyoglobin formation in beef muscles. Meat Sci. 19:151-165.

Reuter, G. 1982. Methods for the identification of meat-quality variations of carcasses. Fleischwirtschaft. 62:1153.

Romans, J. R., and H. W. Norton. 1989. Consumer evaluation of fresh pork quality. Pages 614618 in Proc. 35th Int. Congr. Meat Sci. Technol., Copenhagan, Denmark.

Rosenvold, K., and H. J. Andersen. 2003. The significance of pre-slaughter stress and diet on colour and colour stability of pork. Meat Sci. 63:199-209.

Roserio, L. C., C. Santos, and R. S. Melo. 1994. Muscle pH60, color, (L, a, b) and Water-holding capacity and the influence of postmortem meat temperature. Meat Sci. 38:353-359.

Satterlee, L. D., and N. Y. Zachariah. 1972. Porcine and ovine myoglobin: isolation, purification, characterization and stability. J. Food Sci. 37:909-912.

Sahlin, K., A. Alvestrand, R. Brandt, and E. Hultman. 1978. Intracellular $\mathrm{pH}$ and bicarbonate concentration in human muscle during recovery from exercise. J. Appl. Physiol. 45:474480.

Scheper, R. K. 1971. Research to determine the limits of normal and aberrant meat quality (PSE and DFD) in pork. Pages 271-277 in Proc. 2nd Int. Symp. Condition Meat Quality in pigs. Zeist, Purdoc, Wageningen.

See, M. T., W. E. M. Morrow, K. Zering, J. H. Eisemann, and P. Davies. 2001. Feed withdrawl: Effects on meat quality. North Carolina State Univ. Swine Report.

Sellier, P., and G. Monin. 1994. Genetics of Meat Quality: A review. J. Muscle Foods. 5:187219.

Stahl, C. A., M. S. Carlson-Shannon, B. R. Wiegand, D. L. Meyer, T. B. Schmidt, E. P. Berg. 2007. The influence of creatine and a high glycemic carbohydrate on the growth performance and meat quality of market hogs fed ractopamine hydrochloride. Meat Sci. 75:143-149.

Swatland, H. J. 1982a. Evaluation of pH-related aspects of pork quality by capacitance measurements in an abattoir. Can. J. Anim. Sci. 62:725-730.

Swatland, H. J. 1982b. Meat color of pork chops in relation to $\mathrm{pH}$ and adductor capacitance of intact carcasses. J. Anim. Sci. 54:264-267. 
Swatland, H. J. 1989. Objective measurements of physical aspects of meat quality. Pages 64-73 in Proc. 42nd Recip. Meat Conf., Am. Meat Sci. Assoc., Guelph, Canada.

Swatland, H. J. 2002. Refractometry of pork muscle and beef connective and adipose tissue. Meat Sci. 62:225-228.

Tan, F. J., M. T. Morgan, L. I. Ludas, J. C. Forrest, and D. E. Gerrard. 2000. Assessment of fresh pork color with color machine vision. J. Anim. Sci. 78:3078-3085.

Tarrant, P. V., and C. J. Mothersill. 1977. Glycolysis and associated changes in beef carcasses. J. Sci. Food Agric. 28:739-744.

Thomsen, H. H., and P. Zeuthen. 1988. The influence of mechanically deboned meat and $\mathrm{pH}$ on the water-holding capacity and texture of emulsion type meat products. Meat Sci. 22:189201.

van Laack, R. L. J. M., R. G. Kauffman, W. Sybesma, F. J. M. Smulders, G. Eikelenboom, and J. C. Pinheiro. 1994. Is color brightness (L-value) a reliable indicator of water-holding capacity in porcine muscle? Meat Sci. 38:193-201.

Van Oeckel, M. J., N. van Warrants, and C. V. Boucque. 1999. Measurement and prediction of pork colour. Meat Sci. 52:347-354.

Van Oeckel, M. J., N. van Warrants, C. V. Boucque, P. Delputte, and J. Depuydt. 2001. The preference of the consumer for pork from homozygous or heterozygous halothane negative animals. Meat Sci. 58:247-251.

Velarde, A. M. Gispert, L. Faucitano, P. Alonso, X. Manteca, and A. Diestre. 2001. Effects of the stunning procedure and the halothane genotype on meat quality and incidence of haemorrhages in pigs. Meat Sci. 58:313-319.

Verbeke, W. 2000. Influences on the consumer decision-making process towards fresh meat. British Food Journal. 102:522-538.

Walstra, P., G. Matemann, and P. C. Moerman. 1977. Use of hand-sealer in detecting boar odor in slaughter line. Tijdschrift Voor Diergeneeskunde. 102:913-926.

Warner, R. D., R. G. Kauffman, and R. L. Russell. 1993. Quality attributes of major porcine muscles: a comparison with the longissimus lumborum. Meat Sci. 33:359-372.

Warriss, P. D. 1987. The effect of time and conditions of transport and lairage on pig meat quality. Pages 245-264 in Evaluation and Control of Meat Quality in Pigs. P.V. Tarrent, 
G. Eikelenboom, and G. Monin, eds. Martinus Nijhoff Publishers, Kluwer Academic Publishers, Hingham, MA.

Warriss, P. D., E. A. Bevis, and P. J. Ekins. 1989. The relationships between glycogen stores and muscle $\mathrm{pH}$ in commercially slaughtered pigs. J. Br. Vet. 145:378-383.

Wheeler, T. L., and M. Koohmarie. 1994. Prerigor and postrigor changes in tenderness of ovine longissimus muscle. J. Anim. Sci. 72:1232-1238.

Wiegand, B. R., J. C. Sparks, D. C. Beitz, F. C. Parrish, R. L. Horst, A. H. Trenkle, and R. C. Ewan. 2002. Short-term feeding of vitamin D3 improves pork color but does not change tenderness of pork-loin chops. J. Anim. Sci. 80:2116-2121.

Wierbicki, E., and F. E. Deatherage. 1958. Determination of water-holding capacity of fresh meats. J. Agr. Food Chem. 6:387:393.

Wilborn, B. S., C. R. Kerth, W. F. Owsley, W. R. Jones, and L. T. Frobish. 2004. Improving pork quality by feeding supranutritional concentrations of vitamin D3. J. Anim. Sci. $82: 218-224$.

Wismer-Pedersen, J. 1959. Quality of pork in relation to rate of $\mathrm{pH}$ change post-mortem. Adv. Food Res. 24:711-718.

Wulf, D. M., S. F. O’Connor, J. D. Tatum, and G. C. Smith. 1997. Using objective measures of muscle color to predict beef longissimus tenderness. J. Anim. Sci. 75:684-692.

Yu, L. P., and Y. B. Lee. 1986. Effects of Postmortem pH and Temperature on Bovine Muscle Structure and Meat Tenderness. J. Food Sci. 51:774-780.

Zhu, L. G., and M. S. Brewer. 1998. Metmyoglobin reducing capacity of fresh normal, PSE, and DFD pork during retail display. J. Food Sci. 63:390-393. 


\section{CHAPTER 3 - Materials and Methods}

\section{Population}

\section{General population characteristics}

Two separate hog populations were studied in this project. Both populations were fed a typical corn and soybean diet and harvested at an average live weight of $117.93 \mathrm{~kg}$. Pork carcasses were on the harvest floor for approximately $35 \mathrm{~min}$, in a blast cooler for $75 \mathrm{~min}$, and then entered an equalization bay $\left(-15\right.$ to $\left.-20^{\circ} \mathrm{C}\right)$ until fabrication. Both populations had a similar genetic makeup with white-line females crossed with PIC 337 boars. Therefore, genetic background was not considered a significant factor when developing the prediction equation. Likewise, gender was not considered to be a significant factor when developing the prediction equation, and thus, was not taken into consideration.

The mean, standard deviation, and range for carcass traits are shown for the total population, population one, and population two in Tables 3.1,3.2, and 3.3, respectively. The pork carcass traits were recorded in a commercial abattoir over the course of two years. The total number of observations used in this study was 1465; population one consisted of 781 observations, while population two consisted of 684 observations. Population one was used to explore the relationships between Japanese color score (JCS) and pork-quality attributes (hot carcass weight, backfat, loin depth, percent lean, ham wt, loin wt, boneless loin wt, marbling, firmness, $\mathrm{pH}$, drip loss, $\mathrm{L}^{*}, \mathrm{a}^{*}, \mathrm{~b}^{*}$, hue angle, and chroma) and then to develop an equation to predict JCS. Population two was used to test the prediction equation for accuracy. 
Table 3.1 Carcass traits, total population, $n=1465$

\begin{tabular}{|c|c|c|c|}
\hline Carcass trait & Mean & Standard deviation & Range \\
\hline $\mathrm{HCW}^{\mathrm{a}}, \mathrm{kg}$ & 89.37 & 8.94 & $49.90-120.88$ \\
\hline Backfat, mm & 18.08 & 3.76 & $10.00-33.20$ \\
\hline Loin depth, mm & 59.20 & 6.67 & $24.00-82.80$ \\
\hline Percent lean' & 54.93 & 2.35 & $44.71-61.23$ \\
\hline Ham $^{c}$ wt, kg & 10.71 & 1.04 & $7.21-14.42$ \\
\hline $\operatorname{Loin}^{d}$ wt, kg & 9.50 & 1.02 & $5.51-13.98$ \\
\hline Boneless $\operatorname{loin}^{\mathrm{e}}$ wt, $\mathrm{kg}$ & 3.34 & 0.43 & $1.61-4.98$ \\
\hline Marbling ${ }^{f}$ & 2.30 & 0.56 & $1.00-5.00$ \\
\hline Firmness $^{\mathrm{g}}$ & 2.11 & 0.51 & $1.00-3.00$ \\
\hline pH, ultimate & 5.67 & 0.13 & $5.38-6.61$ \\
\hline Drip loss, \% & 2.57 & 1.91 & $0.05-19.00$ \\
\hline L* (lightness) & 46.84 & 1.96 & $39.37-56.01$ \\
\hline a* (redness) & 6.61 & 1.22 & $2.91-10.56$ \\
\hline b* (yellowness) & -0.03 & 1.20 & $-3.43-4.00$ \\
\hline Hue angle $^{\mathrm{h}}$ & 0.04 & 10.18 & $-27.84-28.12$ \\
\hline Chroma $^{i}$ & 23.31 & 8.46 & $4.50-55.83$ \\
\hline Japanese color score $\mathbf{e}^{\mathrm{j}}$ & 3.16 & 0.50 & $1.00-5.50$ \\
\hline
\end{tabular}

\footnotetext{
${ }^{\mathrm{a}}$ Hot carcass weight.

${ }^{\mathrm{b}}$ Percent lean $=58.86-(0.61 \times$ backfat $)+(0.12 \times$ loin depth $)$.

${ }^{\mathrm{c}}$ Ham: IMPS 401A.

${ }^{\mathrm{d}}$ Loin: IMPS 413.

${ }^{\mathrm{e}}$ Boneless loin: IMPS 414.

${ }^{\mathrm{f}}$ Visual marbling scale: $1=1 \%$ intramuscular lipid, to $10=10 \%$ intramuscular lipid (NPB, 2000).

${ }^{\mathrm{g}}$ Visual firmness: $1=$ soft, to $3=$ firm (NPB, 2000).

${ }^{\mathrm{h}}$ Hue angle: $\left(\mathrm{b}^{*} / \mathrm{a}^{*}\right)^{\tan -1}$; higher values $=$ more brown appearance.

${ }^{\mathrm{i}}$ Chroma: $\left(\mathrm{a}^{2}+\mathrm{b}^{* 2}\right)^{1 / 2}$; higher values $=$ more vivid red color.

${ }^{\mathrm{j}}$ Japanese color score scale: $1=$ light-colored pork, to $6=$ dark-colored pork.
} 
Table 3.2 Carcass traits, population one, $n=781$

\begin{tabular}{|c|c|c|c|}
\hline Carcass trait & Mean & Standard deviation & Range \\
\hline $\mathrm{HCW}^{\mathrm{a}}, \mathrm{kg}$ & 90.80 & 19.02 & $64.00-120.38$ \\
\hline Backfat, mm & 18.79 & 4.20 & $9.60-44.0$ \\
\hline Loin depth, mm & 59.07 & 6.75 & $24.00-89.20$ \\
\hline Percent lean', \% & 54.49 & 2.63 & $39.08-61.23$ \\
\hline $\operatorname{Ham}^{c}$ wt, kg & 10.91 & 2.39 & $14.95-28.30$ \\
\hline Loin $^{d}$ wt, kg & 9.79 & 2.23 & $6.78-13.22$ \\
\hline Boneless loin $^{\mathrm{e}}$ wt, kg & 3.41 & 0.91 & $2.09-4.97$ \\
\hline Marbling ${ }^{f}$ & 2.30 & 0.63 & $1.00-8.00$ \\
\hline Firmness $^{\mathrm{g}}$ & 2.10 & 0.52 & $1.00-3.00$ \\
\hline pH, ultimate & 5.69 & 0.14 & $5.36-6.65$ \\
\hline Drip loss, \% & 2.37 & 1.77 & $0.02-10.61$ \\
\hline L* (lightness) & 47.10 & 3.28 & $37.42-62.22$ \\
\hline a* (redness) & 6.94 & 1.17 & $3.52-12.21$ \\
\hline b* (yellowness) & -0.19 & 1.40 & $-4.45-4.32$ \\
\hline Hue angle ${ }^{h}$ & -0.63 & 10.24 & $-27.84-27.04$ \\
\hline Chroma $^{\mathrm{i}}$ & 22.15 & 8.40 & $4.50-55.71$ \\
\hline Japanese color score $\mathbf{e}^{\mathbf{j}}$ & 3.18 & 0.51 & $1.00-5.00$ \\
\hline
\end{tabular}

\footnotetext{
${ }^{\mathrm{a}}$ Hot carcass weight.

${ }^{\mathrm{b}}$ Percent lean $=58.86-(0.61 \times$ backfat $)+(0.12 \times$ loin depth $)$.

${ }^{\mathrm{c}}$ Ham: IMPS 401A.

${ }^{\mathrm{d}}$ Loin: IMPS 413.

${ }^{\mathrm{e}}$ Boneless loin: IMPS 414.

${ }^{\mathrm{f}}$ Visual marbling scale: $1=1 \%$ intramuscular lipid, to $10=10 \%$ intramuscular lipid (NPB, 2000).

${ }^{\mathrm{g}}$ Visual firmness: $1=$ soft, to $3=$ firm (NPB, 2000).

${ }^{\mathrm{h}}$ Hue angle: $\left(\mathrm{b}^{*} / \mathrm{a}^{*}\right)^{\tan -1}$; higher values $=$ more brown appearance.

${ }^{\mathrm{i}}$ Chroma: $\left(\mathrm{a}^{* 2}+\mathrm{b}^{*^{2}}\right)^{1 / 2}$; higher values $=$ more vivid red appearance.

${ }^{\mathrm{j}}$ Japanese color score scale: $1=$ light-colored pork, to $6=$ dark-colored pork.
} 
Table 3.3 Carcass traits, population two, $\mathrm{n}=684$

\begin{tabular}{|c|c|c|c|}
\hline Carcass trait & Mean & Standard deviation & Range \\
\hline $\mathrm{HCW}^{\mathrm{a}}, \mathrm{kg}$ & 85.78 & 17.07 & $49.80-113.08$ \\
\hline Backfat, mm & 16.96 & 3.96 & $8.40-32.40$ \\
\hline Loin depth, mm & 57.71 & 6.45 & $37.60-90.40$ \\
\hline Percent lean', \% & 55.44 & 2.45 & $45.77-63.56$ \\
\hline $\operatorname{Ham}^{c}$ wt, kg & 10.56 & 2.01 & $7.21-13.34$ \\
\hline Loin $^{d}$ wt, kg & 9.08 & 1.70 & $5.62-11.75$ \\
\hline Boneless loin $^{\mathrm{e}}$ wt, kg & 3.20 & 0.80 & $1.61-4.22$ \\
\hline Marblingf & 2.27 & 0.60 & $1.00-5.00$ \\
\hline Firmness $^{\mathrm{g}}$ & 2.05 & 0.50 & $1.00-3.00$ \\
\hline pH, ultimate & 5.67 & 0.13 & $5.33-6.56$ \\
\hline Drip loss, \% & 2.62 & 1.90 & $-0.57-16.47$ \\
\hline L* (lightness) & 45.29 & 2.86 & $37.16-57.05$ \\
\hline a* (redness) & 5.94 & 1.11 & $2.91-10.89$ \\
\hline b* (yellowness) & -0.26 & 1.35 & $-4.33-4.20$ \\
\hline Hue angle $^{h}$ & 0.83 & 10.05 & $-22.80-28.10$ \\
\hline Chroma $^{i}$ & 24.63 & 8.34 & $5.52-55.81$ \\
\hline Japanese color score ${ }^{j}$ & 3.24 & 0.42 & $1.00-5.50$ \\
\hline
\end{tabular}

\footnotetext{
${ }^{\mathrm{a}}$ Hot carcass weight.

${ }^{\mathrm{b}}$ Percent lean $=58.86-(0.61 \times$ backfat $)+(0.12 \times$ loin depth $)$.

${ }^{\mathrm{c}}$ Ham: IMPS 401A.

${ }^{\mathrm{d}}$ Loin: IMPS 413.

${ }^{\mathrm{e}}$ Boneless loin: IMPS 414.

${ }^{\mathrm{f}}$ Visual marbling scale: $1=1 \%$ intramuscular lipid, to $10=10 \%$ intramuscular lipid (NPB, 2000).

${ }^{\mathrm{g}}$ Visual firmness: 1 = soft, to 3 = firm, $(\mathrm{NPB}, 2000)$.

${ }^{\mathrm{h}}$ Hue angle: $\left(\mathrm{b}^{*} / \mathrm{a}^{*}\right)^{\tan -1}$; higher values $=$ more brown appearance.

${ }^{\mathrm{i}}$ Chroma: $\left(\mathrm{a}^{*^{2}}+\mathrm{b}^{*^{2}}\right)^{1 / 2}$; higher values $=$ more vivid red appearance.

${ }^{\mathrm{j}}$ Japanese color score scale: $1=$ light-colored pork, to $6=$ dark-colored pork.
} 


\section{Carcass traits}

\section{Loin depth and backfat measurements}

A trained evaluator measured loin depth and backfat with a Hennessy Probe (model GP4; Hennessy Grading Systems LTD, Auckland, New Zealand) at the 10th rib on the loin (IMPS 413) at $24 \mathrm{~h}$ postmortem.

\section{Objective color measurements}

Color measurements (CIE L*, a*, b*) were taken in duplicate approximately $26 \mathrm{~h}$ after harvest on the longissimus dorsi of the first chop cut off the sirloin end of the boneless loin (IMPS 414) using a Minolta CR400 with a CR-A33a light projection tube attachment on illuminate C, $2^{\circ}$ observer, $8 \mathrm{~mm}$ aperture (Konica Minolta Sensing, Inc., Osaka, Japan). A single white plate was used to calibrate the instrument. Both the Minolta CR400 and white plate were re-calibrated and checked annually by the manufacturer. Hue angle $\left[\left(b^{*} / a^{*}\right)^{\tan -1}\right]$ and chroma $\left[\left(a^{2}+b^{* 2}\right)^{1 / 2}\right]$ were calculated from instrumental color measurements.

\section{Subjective color measurements}

Subjective color measurements (Japanese Color Score scale, 1 = light-colored pork, to 6 $=$ dark-colored pork) were taken by a trained, two-person panel on the longissimus dorsi on the sirloin end of the boneless loin (IMPS 414). After the initial subjective color measurement was taken on the sirloin end, color on the rib side of the loin was taken into consideration and the final subjective color measurement was adjusted accordingly. Scores were evaluated to the nearest 0.5 of a score.

\section{Marbling}

A trained, two person panel assigned subjective scores for marbling on the longissimus dorsi of the first chop removed from the sirloin end of the boneless loin (IMPS 414) or bone-in loin (IMPS 413) using a continuous scale $(1=1 \%$ intramuscular lipid, $10=10 \%$ intramuscular lipid; NPB, 2000). Photographs of pork chops containing low to high levels of intramuscular fat with standardized numerical marbling scores were used for reference.

\section{Firmness}


A two person, trained panel used a continuous scale $(1=$ soft, cut surfaces distorts easily and are visibly soft; 2 = firm, cut surfaces tend to hold their shape; 3 = very firm, cut surfaces tend to be very smooth with no distortion of shape) to assign subjective scores for firmness (NPB, 2000). The trained panel circumferenced the sirloin end of the boneless loin (IMPS 414) or bone-in loin (IMPS 413) with their hands and evaluated it for firmness and elasticity.

\section{Drip loss calculation}

A second 1.91 to $2.54 \mathrm{~cm}$ thick chop was cut from the sirloin end of the loin and a 2.54 $\mathrm{cm}$ diameter core was removed. To determine drip loss, a core was placed in a meat extract collector tube (Sarstedt, catalog \# 86.290) and held at $2^{\circ} \mathrm{C}$ for $24 \mathrm{~h}$. Drip loss percentage was calculated as follows: $100 \times($ initial core $w t-$ final core $w t) /$ initial core wt.

\section{pH measurements}

A Hanna 98160 pH meter (Hanna Instruments Ltd., Leighton Buzzard, UK) with a FC200B probe was used to measure $\mathrm{pH}$ approximately 26 hours after harvest. The temperature was set at $2^{\circ} \mathrm{C}$ and measurements were taken on the longissimus dorsi muscle in boneless loins (IMPS 414) approximately $5.08 \mathrm{~cm}$ from the sirloin end.

\section{Data analyses}

Relationships between carcass traits and Japanese color score were first explored by performing Pearson's correlations in the CORR procedure of SAS ${ }^{\circledR}$ (2004, version 9.1, SAS Institute, Cary, NC). After Pearson's correlations were run, partial least squares regression (PLS1; Unscrambler ${ }^{\circledR}$ Statistics Software, 2004, version 9.0; Camo Process AS, Oslo, Norway) was run on the traits that were significantly correlated to Japanese color score. PLS1 refers to a multivariate regression technique where a single dependent variable (Japanese Color Score) is modeled using multiple independent variables (instrumental color and carcass traits simultaneously). The correlation loading plot that results from PLS1 indicates the strength of the relationships between the dependent variable and the independent variables. The inner circle in the plot represents $50 \%$ of the variation in the total data set, while the outer ring accounts for the remaining variation $(50 \%)$. The independent variables that are in the outer ring are more strongly correlated to the dependent variable. After the relationships between carcass traits and 
Japanese color score were determined, prediction equations were developed by using multiple linear regression (MLR; Unscrambler ${ }^{\circledR}$ Statistics Software, 2004, version 9.0; Camo Process AS, Oslo, Norway). MLR is a multivariate regression technique that can be used to develop prediction equations from collinear independent variables (carcass traits and instrumental color measurements). A prediction equation was developed by using the color variables and carcass traits that were found significant $(P \leq 0.01)$ in the Pearson's correlations matrix. A second prediction equation was developed using the variables that were in the outer ring of the PLS1 correlation loading plot. A third prediction equation was developed using instrumental color traits $\left(\mathrm{L}^{*}, \mathrm{a}^{*}\right.$, and $\left.\mathrm{b}^{*}\right)$ that can be easily and rapidly measured on-line. 


\section{CHAPTER 4 - Results and discussion}

\section{Correlation studies}

\section{Pearson's correlation}

Pearson's correlation coefficients were calculated on the total population (Table 4.1) between Japanese color score (JCS) and the following traits: hot carcass weight (HCW), backfat, loin depth, percent lean, ham wt, loin wt, boneless loin wt, marbling, firmness, ultimate $\mathrm{pH}$, drip loss, L* (lightness), a* (redness), $\mathrm{b}^{*}$ (yellowness), hue angle, and chroma. A complete correlation table of all traits is in Appendix Table B.

Firmness, ultimate $\mathrm{pH}$, drip loss, $\mathrm{L}^{*}, \mathrm{a}^{*}, \mathrm{~b}^{*}$, hue angle, and chroma were significantly $(P$ $\leq 0.01)$ correlated with JCS, with $L^{*}$ exhibiting the strongest correlation $(-0.87, P \leq 0.0001)$. Hot carcass weight (HCW), backfat, loin depth, percent lean, ham wt, loin wt, boneless loin wt and marbling were not significantly $(P>0.01)$ correlated with JCS. Negative correlations were found for loin depth, percent lean, drip loss, $\mathrm{L}^{*}$ (lightness), $\mathrm{b}^{*}$ (yellowness), and hue angle, while positive correlations were found for $\mathrm{HCW}$, backfat, ham wt, loin wt, boneless loin wt, marbling, firmness, ultimate $\mathrm{pH}, \mathrm{a}^{*}$ (redness), and chroma. Traits which were not significantly correlated $(P>0.01)$ with JCS (HCW, backfat, loin depth, \% lean, ham wt., loin wt., boneless loin wt., and marbling) were eliminated from further statistical evaluation and not included in the prediction equation. 
Table 4.1 Pearson's correlation coefficients for Japanese color score and carcass traits, total population, $\mathrm{n}=1465$

\begin{tabular}{|c|c|c|c|}
\hline Carcass trait & $\mathrm{JCS}^{\mathrm{a}}$ & $P$-value & $\mathbf{N}$ \\
\hline $\mathrm{HCW}^{\mathrm{a}}$ & 0.05 & 0.0730 & 1462 \\
\hline Backfat, mm & 0.03 & 0.2557 & 1400 \\
\hline Loin depth, mm & -0.02 & 0.4288 & 1400 \\
\hline Percent lean ${ }^{\mathrm{b}}$, \% & -0.04 & 0.1680 & 1400 \\
\hline Ham wt ${ }^{\mathrm{c}}, \mathbf{k g}$ & 0.06 & 0.0417 & 1182 \\
\hline Loin wt ${ }^{\mathrm{d}}, \mathbf{k g}$ & 0.03 & 0.2825 & 1230 \\
\hline Boneless loin $\mathrm{wt}^{\mathrm{e}}, \mathrm{kg}$ & 0.01 & 0.6083 & 1230 \\
\hline Marbling ${ }^{\mathrm{f}}$ & 0.06 & 0.0186 & 1465 \\
\hline Firmness ${ }^{\mathrm{g}}$ & 0.13 & $<0.0001$ & 1465 \\
\hline pH, ultimate & 0.41 & $<0.0001$ & 1465 \\
\hline Drip loss, \% & -0.42 & $<0.0001$ & 1465 \\
\hline $\mathrm{L}^{*}$ (lightness) & -0.87 & $<0.0001$ & 1465 \\
\hline$a^{*}$ (redness) & 0.28 & $<0.0001$ & 1465 \\
\hline b* (yellowness) & -0.24 & $<0.0001$ & 1465 \\
\hline Hue angle ${ }^{h}$ & -0.23 & $<0.0001$ & 1465 \\
\hline Chroma $^{\mathrm{i}}$ & 0.29 & $<0.0001$ & 1465 \\
\hline
\end{tabular}

\footnotetext{
${ }^{\mathrm{a}}$ Percent lean $=58.86-(0.61 \times$ backfat $)+(0.12 \times$ loin depth $)$.

${ }^{\mathrm{b}}$ Hot carcass weight.

${ }^{\mathrm{c}}$ Ham: IMPS 401A.

${ }^{\mathrm{d}}$ Loin: IMPS 413.

${ }^{\mathrm{e}}$ Boneless loin: IMPS 414.

${ }^{\mathrm{f}}$ Visual marbling scale: $1=1 \%$ intramuscular lipid, to $10=10 \%$ intramuscular lipid, (NPB, 2000).

${ }^{\mathrm{g}}$ Visual firmness: 1 = soft, to 3 = firm, (NPB, 2000).

${ }^{\mathrm{h}}$ Hue angle: $\left(\mathrm{b}^{*} / \mathrm{a}^{*}\right)^{\mathrm{tan}-1} ;$ higher values $=$ more brown appearance.

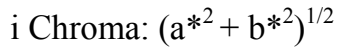




\section{Partial Least Squares Regression}

Partial Least Squares Regression (PLS1) was performed on the traits which were found significant by Pearson's correlation coefficients (firmness, ultimate $\mathrm{pH}$, drip loss $\%, \mathrm{~L}^{*}, \mathrm{a}^{*}, \mathrm{~b}^{*}$, hue angle, and chroma). Preliminary findings found that chroma negatively impacted the $\mathrm{r}^{2}$ of predictive equations and was eliminated from consideration. The resulting correlation loading (Figure 4.1 ) showed that $96 \%$ of the variation in carcass attributes (firmness, ultimate $\mathrm{pH}$, drip loss $\%, L^{*}, a^{*}, b^{*}$, and hue angle) explained $81 \%$ of the variation in Japanese color score in the first two dimensions.

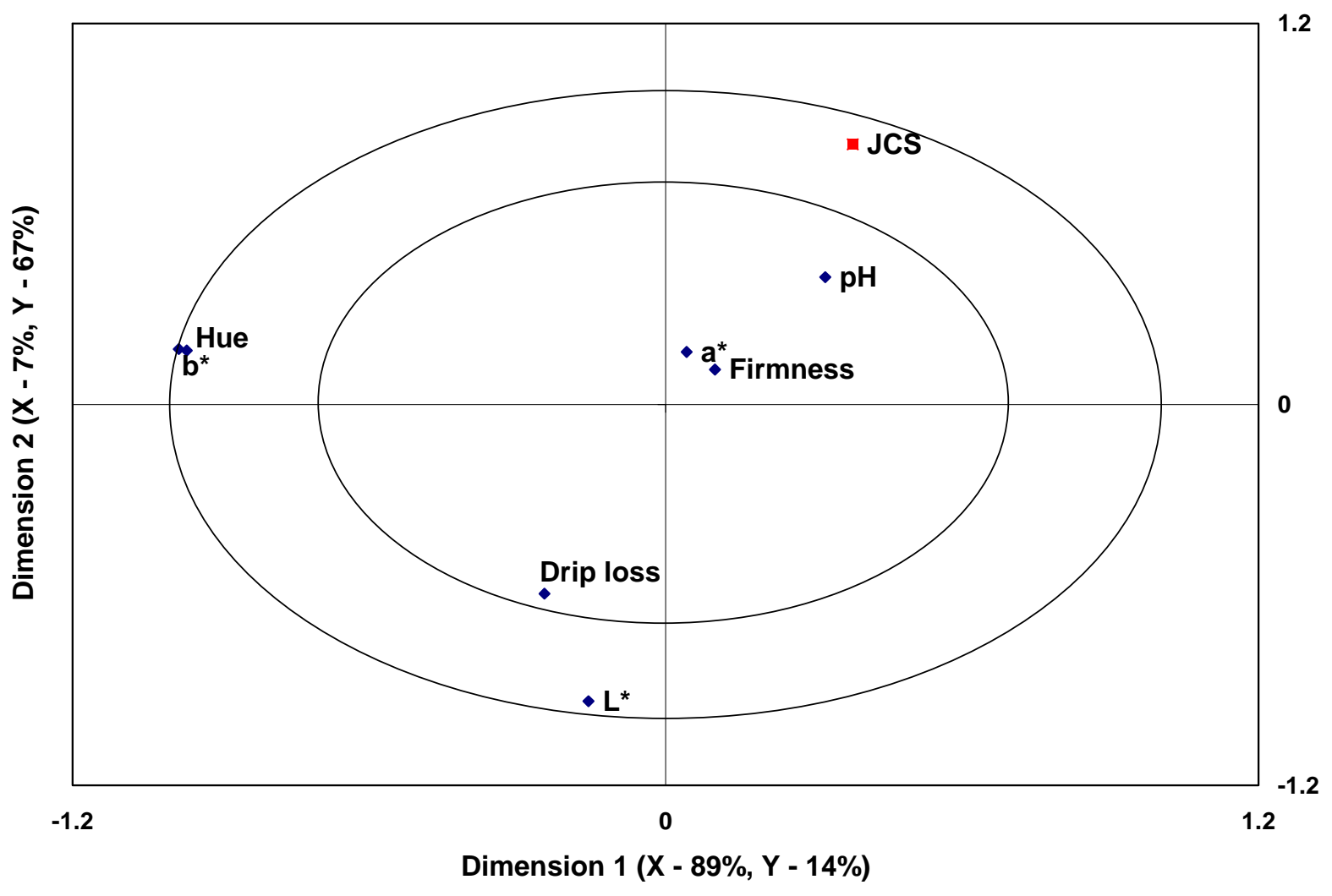

Figure 4.1 Correlation loading of traits found significant by Pearson's correlations

Our PLS1 modeling found that $\mathrm{L}^{*}, \mathrm{~b}^{*}$, and hue angle were the three traits the traits were in the outer ring of the correlation loading and explained the most variability in JCS in the first two dimensions. Similar results were found when carcass traits were compared to JCS by the Pearson's correlations. After examining the Pearson's correlations, we found that $L^{*}(-0.87, P$ 
$<0.0001$ ) had the strongest correlation to JCS. However, we also found that $\mathrm{pH}$ and drip loss were closely correlated with JCS.

Many researchers (Bendall and Swatland, 1988; Swatland, 1982a, b; Penny et al., 1963; Briskey, 1964; Andrews et al., 2007) have indicated that ultimate pH measurements may be directly or indirectly related to many important quality attributes such as color and water-holding capacity. When studying the influence of $\mathrm{pH}$ on pork longissimus dorsi traits, Andrews et al. (2007) found that $L^{*}$ (lightness), $b^{*}$ (yellowness), and percentage purge (drip loss) values linearly decreased with increasing $\mathrm{pH}$ and found that $\mathrm{pH}$ measurements at $24 \mathrm{~h}$ postmortem were useful in predicting color characteristics of aged pork loins.

The relationship of pork color with $\mathrm{pH}$ has been investigated by numerous scientists (Ledward, 1992; Faustman and Cassens, 1990a, b; Ockerman and Cahill, 1977; Zhu and Brewer, 1998; Huff-Lonergan, 2002; Binder et al., 2004). Abattoirs often utilize $\mathrm{pH}$ and instrumental color measurements to estimate quality characteristics (Chizzolini et al., 1993a, b; Wulf et al., 1997; Yu and Lee, 1986; Fjelkner-Modig and Rudérus, 1983; Bouton et al., 1973; Herring et al., 1971).

Generally, carcasses which undergo a gradual, intermediate rate of $\mathrm{pH}$ decline will generally be normal in color, while carcasses that have a rapid $\mathrm{pH}$ decline rate early postmortem will generally be pale in color. Binder et al. (2004) found that initial and ultimate pH influenced the extent of protein denaturation and ultimately, pork quality, especially color and waterholding capacity. They also found that ultimate $\mathrm{pH}$ of the longissimus thoracis could explain $79 \%$ of the variation in subjective color, which increased as $\mathrm{pH}$ increased. Swatland (1989) suggested the possibility that $\mathrm{pH}$ measurements be used to predict pork color after storage.

Roserio et al. (1994) found that as muscle ultimate $\mathrm{pH}$ increased, lightness (L*) decreased while redness $\left(\mathrm{a}^{*}\right)$ and yellowness $\left(\mathrm{b}^{*}\right)$ increased. Correlations between ultimate $\mathrm{pH}$ and CIE $\mathrm{L}^{*}$ and $\mathrm{a}^{*}$ values were fair $(\mathrm{r}=-0.42$ and $\mathrm{r}=0.32$, respectively). A similar relationship between $\mathrm{pH}$ and ultimate pork color was found in our study. A strong correlation was found between $\mathrm{pH}$ and subjective color (JCS) by both multivariate (partial least squares regression, correlation loading) as well as the univariate (Pearson's correlation coefficients) statistical analyses.

For instrumental color measurements, L* (lightness) was more closely correlated with JCS than $\mathrm{b}^{*}$ (yellowness), $\mathrm{a}^{*}$ (lightness), hue angle, and chroma. In a previous investigation, 
Van Oeckel et al. (1999) found JCS was best correlated with the instrumental CIE L* $(r=0.82)$. They also found that Japanese color scores were only slightly better correlated with hue than with CIE $b^{*}$ and $a^{*}$.

In addition, we found firmness was significantly correlated to JCS. This is in agreement with Huff-Lonergan (2002) who found that subjective color was significantly correlated with firmness, concluding that darker product had a greater tendency to be firmer. We found drip loss percentage to be negatively correlated with JCS. This is in agreement with the findings of numerous other researchers whom found relationships between muscle color and water-holding capacity in pork (Wismer-Pederson, 1959; Borggaard et al., 1989; van Laack et al., 1994; Offer et al., 1991). Meat with low pH has also been found to have more exudate (Bendall and WismerPedersen, 1962; Offer and Trinick, 1983).

\section{Predictive Modeling (Equation 1)}

After exploring the relationships between JCS and the carcass attributes using both univariate (Pearson's correlations) and multivariate (partial least squares regression) statistical analyses, a predictive model was developed using traits that were found to be significantly correlated to JCS (firmness, ultimate $\mathrm{pH}$, drip loss $\%, \mathrm{~L}^{*}, \mathrm{a}^{*}, \mathrm{~b}^{*}$, and hue angle). The predictive model was developed in two stages; the first stage was the development of the predictive model using multiple linear regression (population one), while the predictive model was tested for accuracy in the second stage (population two). 


\section{Stage 1}

Average carcass attributes for population one were used to develop the initial prediction equation and are shown in Table 4.2. Averages for each JCS category (1.5, 2.0, 2.5, 3.0, 3.5, 4.0, 4.5 , and 5.0) were calculated and multiple linear regression was run on the averaged data.

Table 4.2 Average carcass traits, population one, $n=781$

\begin{tabular}{|c|c|c|c|c|c|c|c|c|}
\hline $\mathrm{JCS}^{\mathrm{a}}$ & Firmness $^{\mathbf{b}}$ & $\begin{array}{c}\mathrm{pH}, \\
\text { ultimate }\end{array}$ & $\begin{array}{c}\text { Drip loss, } \\
\%\end{array}$ & $\begin{array}{c}\mathrm{L}^{*} \\
\text { (lightness) }\end{array}$ & $\begin{array}{c}\mathrm{a}^{*} \\
\text { (redness) }\end{array}$ & $\begin{array}{c}\mathbf{b}^{*} \\
\text { (yellowness) }\end{array}$ & $\begin{array}{c}\text { Hue } \\
\text { angle }^{\mathrm{c}}\end{array}$ & $\mathbf{N}$ \\
\hline 1.5 & 2.50 & 5.56 & 6.22 & 52.97 & 5.66 & 2.89 & 27.04 & 1 \\
\hline 2.0 & 1.83 & 5.59 & 4.71 & 50.97 & 6.11 & 0.87 & 7.84 & 18 \\
\hline 2.5 & 2.05 & 5.62 & 3.56 & 49.27 & 6.14 & 0.04 & 0.56 & 77 \\
\hline 3.0 & 2.05 & 5.65 & 2.67 & 47.14 & 6.16 & -0.11 & -0.90 & 334 \\
\hline 3.5 & 2.11 & 5.70 & 2.11 & 45.35 & 6.58 & -0.19 & -1.81 & 276 \\
\hline 4.0 & 2.10 & 5.74 & 1.51 & 44.34 & 7.40 & -0.44 & 2.74 & 64 \\
\hline 4.5 & 2.22 & 5.87 & 1.31 & 42.32 & 8.04 & -0.75 & -5.40 & 9 \\
\hline 5.0 & 2.75 & 6.11 & 0.24 & 40.46 & 7.51 & -1.48 & -12.24 & 2 \\
\hline
\end{tabular}

\footnotetext{
${ }^{\mathrm{a}}$ Japanese color score scale: 1 = light-colored pork, to $6=$ dark-colored pork.

${ }^{\mathrm{b}}$ Firmness: 1 = soft, to $3=$ firm.

${ }^{\mathrm{c}}$ Hue angle: $\left(\mathrm{b}^{*} / \mathrm{a}^{*}\right)^{\mathrm{tan}-1}$; higher values $=$ more brown appearance.
}

This resulted in the first prediction equation (eqn 1):

$$
\begin{aligned}
& \text { JCS }=13.060+(0.01180 \times \text { firmness })+(0.06624 \times p H)-(0.001158 \times \text { driploss })-\left(0.0231 \times L^{*}\right) \\
& +\left(0.07185 \times a^{*}\right)-\left(0.193 \times b^{*}\right)+(0.01962 \times \text { hueangle }) ; \mathrm{r}^{2}=0.900 .
\end{aligned}
$$

Data points in population one $(\mathrm{n}=781)$ were run thru eqn 1 to predict JCS. Predicted Japanese color scores which fell within \pm 0.25 of the actual JCS were retained and the rest of the data points were removed. A total of 743 data points were retained while 46 outliers were removed 
from the data set (population one). Table 4.3 shows the number of observations per JCS that were predicted $\pm 0.25, \pm 0.50$, and \pm 0.75 of the actual JCS by eqn 1 , population one.

Table 4.3 Number of Japanese color score predicted $\pm 0.25, \pm 0.50$, and \pm 0.75 of the actual Japanese color score by equation one, population one, $\mathbf{n}=781$

\begin{tabular}{|c|c|c|c|c|c|c|c|}
\hline $\mathrm{JCS}^{\mathbf{a}}$ & $\begin{array}{c}-0.75 \text { to }-0.51 \\
\end{array}$ & -0.50 to -0.26 & -0.25 to 0.00 & 0.00 to 0.25 & 0.26 to 0.50 & 0.51 to $>0.75$ & $\overline{\mathbf{N}}$ \\
\hline 1.5 & & & & 1 & & & 1 \\
\hline 2.0 & & & 6 & 10 & 2 & & 18 \\
\hline 2.5 & & & 47 & 27 & 3 & & 77 \\
\hline 3.0 & & 1 & 194 & 139 & & & 334 \\
\hline 3.5 & & 16 & 148 & 112 & & & 276 \\
\hline 4.0 & & 5 & 51 & & & 1 & 64 \\
\hline 4.5 & & 3 & 5 & 1 & & & 9 \\
\hline 5.0 & & & 2 & & & & 2 \\
\hline
\end{tabular}

a Japanese color score; scale: $1=$ light-colored pork, to $6=$ dark-colored pork.

A total of 760 observations (97.44\%) were predicted within \pm 0.25 of the actual JCS and 780 observations $(99.87 \%)$ were predicted within \pm 0.50 of the actual JCS. The one remaining observation was predicted at $>0.75$. A total of 478 observations $(61.20 \%)$ were predicted within 0.00 to -0.75 of the actual JCS while the remaining 303 observations (38.80\%) were predicted within 0.00 to $>0.75$ of the actual JCS.

Multiple linear regression was run on the retained points $(n=743)$, which resulted in the final prediction model and equation (eqn 2):

$$
\begin{aligned}
& \text { JCS }=12.698-(0.01128 \times \text { firmness })+(0.09008 \times p H)-(0.00007199 \times \text { driploss })-\left(0.266 \times L^{*}\right) \\
& +\left(0.06923 \times a^{*}\right)-\left(0.201 \times b^{*}\right)+(0.02143 \times \text { hueangle }) ; \mathrm{r}^{2}=0.916
\end{aligned}
$$

Table 4.4 shows the distribution of observations per color score predicted $\pm 0.25, \pm 0.50$, and \pm 0.75 of the actual JCS by eqn 2 , population one. 
Table 4.4 Number of Japanese color score predicted $\pm 0.25, \pm 0.50$, and \pm 0.75 of the actual Japanese color score by equation two, population one, $n=781$

\begin{tabular}{|c|c|c|c|c|c|c|c|}
\hline$\overline{\text { JCS }^{\mathbf{a}}}$ & 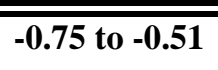 & -0.50 to -0.26 & $\overline{-0.25 \text { to } 0.00}$ & $\overline{0.00 \text { to } 0.25}$ & 0.26 to 0.50 & 0.51 to $>0.75$ & $\mathbf{N}$ \\
\hline 1.5 & & & & 1 & & & 1 \\
\hline 2.0 & & & 4 & 11 & 3 & & 18 \\
\hline 2.5 & & & 38 & 36 & 3 & & 77 \\
\hline 3.0 & & 1 & 153 & 180 & & & 334 \\
\hline 3.5 & & 21 & 149 & 106 & & & 276 \\
\hline 4.0 & & & 35 & 15 & & 1 & 64 \\
\hline 4.5 & & 5 & 3 & 1 & & & 9 \\
\hline 5.0 & 1 & 1 & & & & & 2 \\
\hline
\end{tabular}

${ }^{\mathrm{a}}$ Japanese color score; scale: $1=$ light-colored pork, to $6=$ dark-colored pork.

Population one was run thru eqn 2 to predict JCS. A total of 732 observations $(93.72 \%)$ were predicted within \pm 0.25 of the actual JCS and 779 observations (99.79\%) predicted within \pm 0.25 of the actual JCS. The remaining 2 observations were predicted within \pm 0.51 to $> \pm 0.75$ of the actual JCS. A total of 411 observations (52.62\%) were predicted within 0.00 to -0.75 of the actual JCS while the remaining 370 observations (47.38\%) were predicted within 0.00 to $>$ 0.75 of the actual JCS. 


\section{Stage 2}

Population two $(n=684)$ served as the test data set in order to validate the prediction model and equation (eqn 2) developed in stage 1.

Table 4.5 Number of Japanese color score (JCS) predicted $\pm 0.25, \pm 0.50$, and \pm 0.75 of the actual JCS by equation two, population two, $n=684$

\begin{tabular}{|c|c|c|c|c|c|c|c|}
\hline $\mathrm{JCS}^{\mathbf{a}}$ & -0.75 to -0.51 & -0.50 to -0.26 & -0.25 to 0.00 & $\overline{0.00 \text { to } 0.25}$ & $\overline{0.26 \text { to } 0.50}$ & 0.51 to 0.75 & $\mathbf{N}$ \\
\hline 1.0 & & & & 1 & 1 & & 2 \\
\hline 1.5 & & & 1 & 1 & & & 2 \\
\hline 2.0 & & & 8 & 13 & 3 & 1 & 25 \\
\hline 2.5 & 1 & 8 & 55 & 38 & 13 & 2 & 117 \\
\hline 3.0 & 5 & 57 & 107 & 86 & 42 & & 297 \\
\hline 3.5 & & 53 & 78 & 40 & 6 & & 180 \\
\hline 4.0 & & 15 & 20 & 9 & 4 & & 48 \\
\hline 4.5 & 1 & 6 & 1 & 1 & & & 9 \\
\hline 5.0 & & 2 & 1 & & & & 3 \\
\hline 5.5 & & 1 & & & & & 1 \\
\hline
\end{tabular}

a Japanese color score; scale: $1=$ light-colored pork, to $6=$ dark-colored pork.

Population two was run thru eqn 2 to predict JCS. A total of 460 observations $(67.25 \%)$ were predicted within \pm 0.25 of the actual JCS and 674 observations (98.53\%) were predicted within \pm 0.50 of the actual JCS. The remaining 10 observations were predicted within \pm 0.51 to \pm 0.75 of the actual JCS. A total of 420 observations $(61.40 \%)$ were predicted within 0.00 to 0.75 of the actual JCS while the remaining 254 observations (37.13\%) were predicted within 0.00 to 0.75 of the actual JCS. For both equations, more observations from population one were predicted within \pm 0.50 of the actual JCS than observations from population two. These results would be expected as the prediction equations were made using observations from population one, so they should be more able to accurately predict JCS. 
Rapidly measuring all traits which were part of the prediction equation/model would not be practical, as some of the traits are invasive and time-consuming to measure. Therefore, equations were developed using instrumental color traits (CIE L*, a*, $b^{*}$, and hue angle) that are easily and rapidly measured on-line. 


\section{Prediction Equations Utilizing Only Instrumental Color}

Rapidly measuring all traits which were part of the first prediction equation would not be practical, as some of the traits are invasive and time-consuming to measure. Therefore, two additional prediction equations were developed using instrumental color traits that are easily and rapidly measured on-line. The second equation was developed using instrumental color traits of $L^{*}, b^{*}$, and hue angle). These traits were selected as they represented the traits found to have the strongest predictive value for Japanese color score as found by PLS1 (Figure 4.1). A third equation was developed utilizing instrumental color traits of $\mathrm{L}^{*}, \mathrm{a}^{*}$, and $\mathrm{b}^{*}$. These traits were selected to simplify the equation recognizing that the calculation of hue angle $\left[\left(\mathrm{b}^{*} / \mathrm{a}^{*}\right)^{\tan -1}\right]$ includes both $\mathrm{a}^{*}$ and $\mathrm{b}^{*}$.

Using statistical analyses as previously described, the prediction equations were developed in two stages; the first stage was the development of the predictive model using multiple linear regression (population one), while the prediction equations were tested for accuracy in the second stage (population two). 


\section{Equation Two}

\section{Stage 1}

Average carcass attributes for population one were used to develop the prediction equation and are shown in Table 4.6. Averages for each JCS category (1.5, 2.0, 2.5, 3.0, 3.5, 4.0, 4.5, and 5.0) were calculated, and multiple linear regression was run on the averaged data.

Table 4.6 Average carcass traits for population one, $n=781$

\begin{tabular}{ccccc}
\hline \hline $\mathbf{J C S}^{\mathbf{a}}$ & $\mathbf{L}^{*}$ (lightness) & $\mathbf{b}^{*}$ (yellowness) & Hue angle $^{\mathbf{b}}$ & $\mathbf{N}$ \\
\hline $\mathbf{1 . 5}$ & 52.97 & 2.89 & 27.04 & 1 \\
$\mathbf{2 . 0}$ & 50.97 & 0.87 & 7.84 & 18 \\
$\mathbf{2 . 5}$ & 49.27 & 0.04 & 0.56 & 77 \\
$\mathbf{3 . 0}$ & 47.14 & -0.11 & -0.90 & 334 \\
$\mathbf{3 . 5}$ & 45.35 & -0.19 & -1.81 & 276 \\
$\mathbf{4 . 0}$ & 44.34 & -0.44 & 2.74 & 64 \\
$\mathbf{4 . 5}$ & 42.32 & -0.75 & -5.40 & 9 \\
$\mathbf{5 . 0}$ & 40.46 & -1.48 & -12.24 & 2 \\
\hline
\end{tabular}

\footnotetext{
a Japanese color score scale: 1 = light-colored pork, to $6=$ dark-colored pork.
}

${ }^{\mathrm{b}}$ Hue angle: $\left(\mathrm{b}^{*} / \mathrm{a}^{*}\right)^{\mathrm{tan}-1}$; higher values $=$ more brown appearance.

This resulted in the first prediction equation (eqn 1):

$$
J C S=16.639-\left(0.288 \times L^{*}\right)-\left(0.188 \times b^{*}\right)+(0.02407 \times \text { hueangle }) ; \mathrm{r}^{2}=0.999 \text {. }
$$

Data points in population one $(\mathrm{n}=781)$ were run thru eqn 1 to predict JCS. Predicted JCS which fell within \pm 0.25 of the actual Japanese color scores were retained; 606 data points were retained while 175 outliers were removed from the data set (population one). Table 4.7 shows the distribution of observations per color score predicted $\pm 0.25, \pm 0.50$, and \pm 0.75 of the actual JCS by equation one, population one. 
Table 4.7 Number of Japanese color score predicted $\pm 0.25, \pm 0.50$, and \pm 0.75 of the actual Japanese color score by equation one, population one, $\mathbf{n}=781$

\begin{tabular}{|c|c|c|c|c|c|c|c|}
\hline $\mathrm{JCS}^{\mathrm{a}}$ & -0.75 to -0.51 & -0.50 to -0.26 & -0.25 to 0.00 & 0.00 to 0.25 & 0.26 to 0.50 & 0.51 to 0.75 & $\mathbf{N}$ \\
\hline 1.5 & & & 1 & & & & 1 \\
\hline 2.0 & & & 8 & 8 & 2 & & 18 \\
\hline 2.5 & & 8 & 37 & 28 & 4 & & 77 \\
\hline 3.0 & & 18 & 102 & 154 & 60 & & 334 \\
\hline 3.5 & & 14 & 80 & 131 & 51 & & 276 \\
\hline 4.0 & 1 & 5 & 24 & 25 & 8 & 1 & 64 \\
\hline 4.5 & & 3 & & 6 & & & 9 \\
\hline 5.0 & & & 1 & 1 & & & 2 \\
\hline
\end{tabular}

${ }^{\mathrm{a}}$ Japanese color score; scale: $1=$ light-colored pork, to $6=$ dark-colored pork.

A total of 606 observations (77.59\%) were predicted within \pm 0.25 of the actual JCS and 779 observations $(99.74 \%)$ were predicted within \pm 0.50 of the actual JCS. The remaining 2 observations were predicted within \pm 0.51 to \pm 0.75 of the actual JCS. A total of 302 observations $(38.67 \%)$ were predicted within 0.00 to -0.75 of the actual JCS while the remaining 479 observations $(61.33 \%)$ were predicted within 0.00 to 0.75 of the actual JCS.

Multiple linear regression was run on the retained points $(n=606)$, which resulted in the final prediction model and equation (eqn 2);

$J C S=15.255-\left(0.259 \times L^{*}\right)-\left(0.213 \times b^{*}\right)+(0.02518 \times$ hueangle $) ; \mathrm{r}^{2}=0.931$. Table 4.8 shows the distribution of observations per color score predicted $\pm 0.25, \pm 0.50$, and \pm 0.75 of the actual JCS by eqn 2 in population one. 
Table 4.8 Number of Japanese color score predicted $\pm 0.25, \pm 0.50$, and \pm 0.75 of the actual Japanese color score by equation two, population one, $\mathbf{n}=781$

\begin{tabular}{|c|c|c|c|c|c|c|c|}
\hline$\overline{J_{C S}}{ }^{\mathbf{a}}$ & -0.75 to -0.51 & -0.50 to -0.26 & -0.25 to 0.00 & 0.00 to 0.25 & 0.26 to 0.50 & 0.51 to 0.75 & $\mathbf{N}$ \\
\hline 1.5 & & & & 1 & & & 1 \\
\hline 2.0 & & & 6 & 10 & 2 & & 18 \\
\hline 2.5 & & 3 & 43 & 31 & & & 77 \\
\hline 3.0 & & 13 & 111 & 168 & 42 & & 334 \\
\hline 3.5 & & 17 & 118 & 118 & 23 & & 276 \\
\hline 4.0 & 1 & 8 & 30 & 23 & 1 & 1 & 64 \\
\hline 4.5 & & 3 & 4 & 2 & & & 9 \\
\hline 5.0 & & 1 & 1 & & & & 2 \\
\hline
\end{tabular}

${ }^{\mathrm{a}}$ Japanese color score; scale: $1=$ light-colored pork to $6=$ dark-colored pork.

A total of 666 observations (82.28\%) were predicted within \pm 0.25 of the actual JCS and 779 observations $(99.74 \%)$ were predicted within \pm 0.50 of the actual JCS. The remaining 2 observations were predicted within \pm 0.51 to \pm 0.75 of the actual JCS. A total of 359 observations were predicted within 0.00 to -0.75 of the actual JCS while the remaining 422 observations were predicted within 0.00 to 0.75 of the actual JCS. 


\section{Stage 2}

Population two $(\mathrm{n}=684)$ served as the test data set in order to validate the prediction equation developed in stage 1 (eqn 2). Table 4.9 shows the distribution of observations per color scores that were predicted $\pm 0.25, \pm 0.50$, and \pm 0.75 of the actual JCS by eqn 2 in population two.

Table 4.9 Number of Japanese color score predicted $\pm 0.25, \pm 0.50$, and \pm 0.75 of the actual Japanese color score by equation two, population two, $n=684$

\begin{tabular}{cccccccc}
\hline \hline $\mathbf{J C S}^{\mathbf{a}}$ & $\mathbf{- 0 . 7 5}$ to $\mathbf{- 0 . 5 1}$ & $\mathbf{- 0 . 5 0}$ to $\mathbf{- 0 . 2 6}$ & $\mathbf{- 0 . 2 5}$ to 0.00 & $\mathbf{0 . 0 0}$ to 0.25 & $\mathbf{0 . 2 6}$ to 0.50 & $\mathbf{0 . 5 1}$ to 0.75 & $\mathbf{~ N}$ \\
\hline $\mathbf{1 . 0}$ & & 1 & & 1 & & & 2 \\
$\mathbf{1 . 5}$ & & 1 & & 1 & & & 2 \\
$\mathbf{2 . 0}$ & 1 & 1 & 10 & 8 & 4 & 1 & 25 \\
$\mathbf{2 . 5}$ & 3 & 18 & 50 & 26 & 16 & 4 & 117 \\
$\mathbf{3 . 0}$ & 14 & 66 & 91 & 66 & 53 & 7 & 297 \\
$\mathbf{3 . 5}$ & 13 & 50 & 56 & 44 & 17 & & 180 \\
$\mathbf{4 . 0}$ & 6 & 14 & 16 & 11 & 1 & & 48 \\
$\mathbf{4 . 5}$ & 3 & 4 & & 1 & 1 & & 9 \\
$\mathbf{5 . 0}$ & & 3 & & & & & 3 \\
$\mathbf{5 . 5}$ & & 1 & & & & & 1 \\
\hline
\end{tabular}

${ }^{\mathrm{a}}$ Japanese color score; scale: $1=$ light-colored pork, to $6=$ dark-colored pork.

A total of 381 observations (55.70\%) were predicted within \pm 0.25 of the actual JCS and 632 observations $(92.40 \%)$ were predicted within \pm 0.50 of the actual JCS. The remaining 52 observations were predicted within \pm 0.51 to \pm 0.75 of the actual JCS. A total of 422 observations were predicted within 0.00 to -0.75 of the actual JCS while the remaining 262 observations were predicted within 0.00 to 0.75 of the actual JCS. For both equations, more observations from population one were predicted within \pm 0.50 of the actual JCS than observations from population two. These results would be expected as the prediction equations were made using observations from population one, so the equations should more accurately predict JCS for population one than population two. 


\section{Equation Three}

A predictive model was developed using instrumental color traits (CIE L*, a*, and $b^{*}$ ) that can be easily and rapidly measured on-line. The predictive model was developed in two stages; the first stage was the development of the predictive model using multiple linear regression (population one), while the predictive model was tested for accuracy in the second stage (population two).

\section{Stage 1}

Average carcass attributes for population one were used to develop the prediction equation and are shown in Table 4.10 below. Averages for each JCS category $(1.5,2.0,2.5,3.0$, $3.5,4.0,4.5$, and 5.0) were calculated, and multiple linear regression was run on the averaged data.

Table 4.10 Average carcass traits for population one, $n=781$

\begin{tabular}{ccccc}
\hline \hline JCS $^{\mathbf{a}}$ & $\mathbf{L}^{*}$ (lightness) & $\mathbf{a}^{*}$ (redness) & $\mathbf{b}^{*}$ (yellowness) & $\mathbf{N}$ \\
\hline $\mathbf{1 . 5}$ & 52.97 & 5.66 & 2.89 & 1 \\
$\mathbf{2 . 0}$ & 50.97 & 6.11 & 0.87 & 18 \\
$\mathbf{2 . 5}$ & 49.27 & 6.14 & 0.04 & 77 \\
$\mathbf{3 . 0}$ & 47.14 & 6.16 & -0.11 & 334 \\
$\mathbf{3 . 5}$ & 45.35 & 6.58 & -0.19 & 276 \\
$\mathbf{4 . 0}$ & 44.34 & 7.40 & -0.44 & 64 \\
$\mathbf{4 . 5}$ & 42.32 & 8.04 & -0.75 & 9 \\
$\mathbf{5 . 0}$ & 40.46 & 7.51 & -1.48 & 2 \\
\hline
\end{tabular}

a Japanese color score scale: 1 = light-colored pork, to $6=$ dark-colored pork.

This resulted in the first prediction equation (eqn 1):

$J C S=13.406-\left(0.230 \times L^{*}\right)+\left(0.07941 \times a^{*}\right)-\left(0.03607 \times b^{*}\right) ; r^{2}=0.868$. 
Data points in population one $(n=781)$ were run thru eqn 1 to predict JCS. Predicted JCS which fell within \pm 0.25 of the actual Japanese color scores were retained; 704 data points were retained while 77 outliers were removed from the data set (population one). Table 4.11 shows the distribution of observations per color score predicted $\pm 0.25, \pm 0.50$, and \pm 0.75 of the actual JCS by equation one, population one. 
Table 4.11 Number of Japanese color score predicted $\pm 0.25, \pm 0.50$, and \pm 0.75 of the actual Japanese color score by equation one, population one, $\mathbf{n}=781$

\begin{tabular}{|c|c|c|c|c|c|c|c|}
\hline $\mathrm{JCS}^{\mathrm{a}}$ & -0.75 to -0.51 & -0.50 to -0.26 & -0.25 to 0.00 & 0.00 to 0.25 & 0.26 to 0.50 & 0.51 to 0.75 & $\mathbf{N}$ \\
\hline 1.5 & & & & 1 & & & 1 \\
\hline 2.0 & & & 5 & 7 & 6 & & 18 \\
\hline 2.5 & & 2 & 27 & 38 & 10 & & 77 \\
\hline 3.0 & & 2 & 113 & 202 & 17 & & 334 \\
\hline 3.5 & & 4 & 134 & 134 & 4 & & 276 \\
\hline 4.0 & 8 & 18 & 23 & 13 & 2 & & 64 \\
\hline 4.5 & & 3 & 5 & 1 & & & 9 \\
\hline 5.0 & & 1 & 1 & & & & 2 \\
\hline
\end{tabular}

a Japanese color score; scale: $1=$ light-colored pork, to $6=$ dark-colored pork.

A total of 704 observations (90.14\%) were predicted within \pm 0.25 of the actual JCS and 773 observations $(98.98 \%)$ ) were predicted within \pm 0.50 of the actual JCS. The remaining 8 observations were predicted within \pm 0.51 to \pm 0.75 of the actual JCS. A total of 346 observations $(44.30 \%)$ were predicted within 0.00 to -0.75 of the actual JCS while the remaining 435 observations $(55.70 \%)$ were predicted within 0.00 to 0.75 of the actual JCS.

Multiple linear regression was run on the retained points $(n=704)$, which resulted in the final prediction model and equation (eqn 2);

$J C S=12.920-\left(0.219 \times L^{*}\right)+\left(0.07342 \times a^{*}\right)-(0.02166 \times b *) ; \mathrm{r}^{2}=0.906$. Table 4.12 shows the distribution of observations per color score predicted $\pm 0.25, \pm 0.50$, and \pm 0.75 of the actual JCS by eqn 2 in population one. 
Table 4.12 Number of Japanese color score predicted $\pm 0.25, \pm 0.50$, and \pm 0.75 of the actual Japanese color score by equation two, population one, $\mathbf{n}=781$

\begin{tabular}{|c|c|c|c|c|c|c|c|}
\hline $\mathrm{JCS}^{\mathbf{a}}$ & -0.75 to -0.51 & -0.50 to -0.26 & -0.25 to 0.00 & 0.00 to 0.25 & 0.26 to 0.50 & 0.51 to 0.75 & $\mathbf{N}$ \\
\hline 1.5 & & & & 1 & & & 1 \\
\hline 2.0 & & & 3 & 9 & 6 & & 18 \\
\hline 2.5 & & & 25 & 40 & 12 & & 77 \\
\hline 3.0 & & & 120 & 203 & 11 & & 334 \\
\hline 3.5 & & 6 & 146 & 124 & & & 276 \\
\hline 4.0 & 10 & 20 & 25 & 7 & 2 & & 64 \\
\hline 4.5 & 1 & 2 & 6 & & & & 9 \\
\hline 5.0 & & 2 & & & & & 2 \\
\hline
\end{tabular}

a Japanese color score; scale: $1=$ light-colored pork, to $6=$ dark-colored pork.

A total of 709 observations (90.78\%) were predicted within \pm 0.25 of the actual JCS and 770 observations $(98.59 \%)$ were predicted within \pm 0.50 of the actual JCS. The remaining 11 observations were predicted within \pm 0.51 to \pm 0.75 of the actual JCS. A total of 366 observations were predicted within 0.00 to -0.75 of the actual JCS while the remaining 415 observations were predicted within 0.00 to 0.75 of the actual JCS. 


\section{Stage 2}

Population two $(\mathrm{n}=684)$ served as the test data set in order to validate the prediction equation developed in stage 1 (eqn 2). Table 4.13 shows the distribution of observations per color scores that were predicted $\pm 0.25, \pm 0.50$, and \pm 0.75 of the actual JCS by eqn 2 in population two.

Table 4.13 Number of Japanese color score predicted $\pm 0.25, \pm 0.50$, and \pm 0.75 of the actual Japanese color score by equation two, population two, $n=684$

\begin{tabular}{cccccccc}
\hline \hline JCS $^{\text {a }}$ & $-\mathbf{- 0 . 7 5}$ to -0.51 & $\mathbf{- 0 . 5 0 ~ t o ~}-\mathbf{0 . 2 6}$ & $\mathbf{- 0 . 2 5 ~ t o ~ 0 . 0 0}$ & $\mathbf{0 . 0 0}$ to 0.25 & $\mathbf{0 . 2 6}$ to 0.50 & $\mathbf{0 . 5 1}$ to 0.75 & $\mathbf{N}$ \\
\hline $\mathbf{1 . 0}$ & & 1 & & & 1 & & 2 \\
$\mathbf{1 . 5}$ & & & & 1 & 1 & & 2 \\
$\mathbf{2 . 0}$ & & & 7 & 11 & 5 & 2 & 25 \\
$\mathbf{2 . 5}$ & & 2 & 42 & 51 & 20 & 2 & 117 \\
$\mathbf{3 . 0}$ & & 42 & 109 & 96 & 48 & 2 & 297 \\
$\mathbf{3 . 5}$ & 1 & 50 & 76 & 42 & 11 & & 180 \\
$\mathbf{4 . 0}$ & 4 & 15 & 21 & 8 & & & 48 \\
$\mathbf{4 . 5}$ & 3 & 4 & 1 & 1 & & & 9 \\
$\mathbf{5 . 0}$ & & 3 & & & & & 3 \\
$\mathbf{5 . 5}$ & 1 & & & & & & 1 \\
\hline
\end{tabular}

a Japanese color score; scale: 1 = light-colored pork, to $6=$ dark-colored pork.

A total of 466 observations (68.12\%) were predicted within \pm 0.25 of the actual JCS and 669 observations $(97.80 \%)$ were predicted within \pm 0.50 of the actual JCS. The remaining 15 observations were predicted within \pm 0.51 to \pm 0.75 of the actual JCS. A total of 385 observations were predicted within 0.00 to -0.75 of the actual JCS while the remaining 299 observations were predicted within 0.00 to 0.75 of the actual JCS. For both equations, more observations from population one were predicted within \pm 0.50 of the actual JCS than observations from population two. These results would be expected as the prediction equations were made using observations from population one, so the equations should more accurately predict JCS for population one than population two. 


\section{Conclusion}

With an increase in worldwide pork consumption, it is important to understand that cultural and preference differences that exist among pork consumers. Across numerous countries, consumer studies (Cipolli et al., 2003; Cho et al., 2007; Ngapo et al., 2004; Glitsch, 2000) have found color as the single most important criteria used during the selection of pork. Although many consumers cite color as the most important factor they consider when purchasing pork, their preference for pork color differs. For instance, Japanese consumers are particularly fond of firmer, redder pork and are willing to pay premiums to receive such pork (van Heugten, 2001). Japanese consumers tend to equate high cost with high quality, and have clear ideas about meat quality characteristics that must be met. With the growing number of more affluent Asian consumers, processors can not ignore the importance of the Asian export markets and must supply pork which meets their specific needs.

Pork quality traits are influenced by several antemortem and postmortem factors which makes the prediction of ultimate pork quality a difficult task. Analysis of various pork carcass characteristics and their relationship to Japanese color score was completed and three equations to predict JCS were developed. A summary of prediction equations developed in this project are shown in Table 4.14. It is worthy to note that the original data were scored to the nearest 0.50 .

Table 4.14 Summary of prediction equations developed

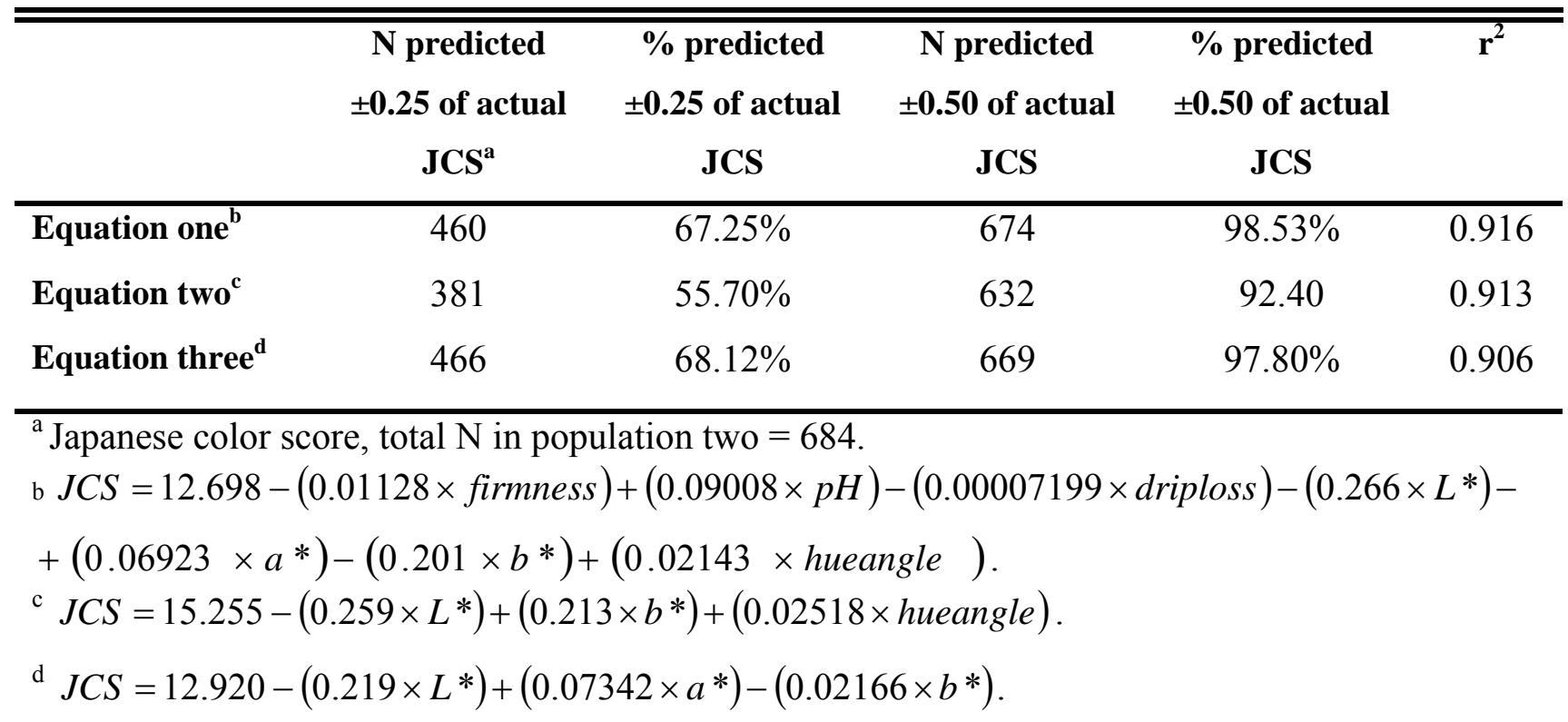


The first prediction equation $\left(r^{2}=0.916\right)$ was developed using pork loin characteristics (drip loss percentage, ultimate $\mathrm{pH}$, firmness, $\mathrm{L}^{*}, \mathrm{a}^{*}, \mathrm{~b}^{*}$ and hue angle) that were significantly correlated to Japanese color score. On a second test population, the resulting equation predicted $460(67.25 \%)$ of the Japanese color scores within \pm 0.25 , and $674(98.53 \%)$ of the Japanese color scores within \pm 0.50 .

However, rapidly measuring all traits which were part of the prediction equation/model would not be practical (i.e., drip loss is an invasive and time consuming trait to measure). Therefore, two additional prediction equations were developed using instrumental color traits $\left(\mathrm{L}^{*}, \mathrm{~b}^{*}\right.$, and hue angle) which are easily and rapidly measured on-line. These traits were selected as they represented the traits found to have the strongest predictive value for Japanese color score as found by PLS1. On the test population, the second equation $\left(r^{2}=0.931\right)$, based entirely on instrumental color measurements ( $\mathrm{L}^{*}, \mathrm{~b}^{*}$, and hue angle), was able to predict 381 $(55.70 \%)$ of the Japanese color scores within \pm 0.25 , and $632(92.40 \%)$ of the actual Japanese color score within \pm 0.50 . These traits were selected to simplify the equation recognizing that the calculation of hue angle includes both $a^{*}$ and $b^{*}$. The third prediction equation $\left(r^{2}=0.906\right)$, was developed based entirely on instrumental color measurements $\left(\mathrm{L}^{*}, \mathrm{a}^{*}\right.$, and $\left.\mathrm{b}^{*}\right)$. Equation three predicted $466(68.12 \%)$ of the Japanese color scores within \pm 0.25 , and $669(97.80 \%)$ of the actual Japanese color scores within \pm 0.50 .

All prediction equations predicted Japanese color score within \pm 0.50 more than $92 \%$ of the time and would be useful when sorting pork carcasses for export to valuable Asian markets. The second and third prediction equations (developed using instrumental color traits) would be advantageous as they require fewer measurements and could be more rapidly collected. 


\section{Literature Cited}

Andrews, B. S., S. Hutchison, J. A. Unruh, M. C. Hunt, J. E. Boyer, JR., and R. C. Johnson. 2007. Influence of $\mathrm{pH}$ at $24 \mathrm{~h}$ postmortem on quality characteristics of pork loins aged 45 days postmortem. J. Muscle Foods. 18:401-419.

Bendall, J. R., and H. J. Swatland. 1988. A review of the relationships of $\mathrm{pH}$ with physical aspects of pork quality. Meat Sci. 24:85-126.

Bendall, J. R., and J. Wismer-Pedersen. 1962. Some properties of the fibrillar proteins of normal and watery pork muscle. J. Food Sci. 27:144-157.

Binder, B. S., M. Ellis, M. S. Brewer, D. Campion, E. R. Wilson, F. K. McKeith. 2004. Effect of ultimate $\mathrm{pH}$ on the quality characteristics of pork. J. Muscle Foods. 15:139-154.

Borggaard, C., J. P. Anderson, and P. Barton-Gade. 1989. Further development of the MQMequipment for measuring water-holding capacity and intramuscular fat on-line. Pages 212-219 in Proc. 35th Int. Congr. Meat Sci. Technol., Copenhagan, Denmark.

Bouton, P. E., R. D. Carroll, P. V. Harris, and W. R. Shorthose. 1973. Influence of pH and fiber contraction state upon factors affecting tenderness of bovine muscles. J. Food Sci. 38:404-407.

Briskey, E. J. 1964. Etiological status and associated studies of pale, soft, exudative porcine musculature. Adv. Food Res. 13:89-168.

Chizzolini, R., E. Noveli, A. Badiani, P. Rosa, and G. Delbono. 1993a. Objective measurements of pork quality: Evaluation of various techniques. Meat Sci. 34:49-77.

Chizzolini, R., E. Noveli, A. Badiani, G. Delbono, and P. Rosa. 1993b. Objective measurements of pork quality: Evaluation of on-line techniques. Meat Sci. 34:79-93.

Cho, S., B. Park, T. Ngapo, J. Kim, E. Dransfield, I. Hwang, and J. Lee. 2007. Effect of meat appearance on South Korean consumers' choice of pork chops determined by image methodology. J. Sensory Studies. 22:99-114.

Cipolli, K. M.V. A., E. T. Silveira, T. M. Ngapo, and E. Dransfield. 2003. Consumer preferences of pork chops - the Brazilian study. Abstract. Page 187 in $5^{\text {th }}$ Pangborn sensory science symposium, Boston, U.S.A.

Faustman, C., and R. G. Cassens. 1990a. Influence of aerobic metmyoglobin reducing capacity on color stability of beef. J. Food Sci. 55:1278-1283. 
Faustman, C., and R. G. Cassens. 1990b. The biochemical basis for discoloration in fresh meat: a review. J. Muscle Foods. 1:217-243.

Fjelkner-Modig, S., and H. Rudérus. 1983. The influence of exhaustion and electrical stimulation on meat quality of young bulls: Part 2-Physical and sensory properties. Meat Sci. 8:203202.

Glitsch, K. 2000. Consumer perceptions of fresh meat quality: cross-national comparison. British Food Journal. 103:177-194.

Herring, H. K., J. H. Haggard, and L. J. Hansen. 1971. Studies on chemical and physical properties of pork in relation to quality. J. Anim. Sci. 33:578-586.

Huff-Lonergan, E., T. J. Baas, M. Malek, J. C. M. Dekkers, K. Prusa, and M. F. Rothschild. 2002. Correlations among selected pork quality traits. J. Anim. Sci. 80:617-627.

Ledward, D. A. 1992. Colour of raw and cooked meat. Pages 128-144 in The Chemistry of Muscle-based foods. Ledward, D. A., D. E. Johnston, and M. Knight, eds. Royal Society of Chemistry, London, England.

NPB. 2000. National Pork Board as implemented by the National Pork Producers Council. Pork composition and quality assessment procedures. Des Moines, IA.

Ngapo, T. M., J. F. Martin, and E. Dransfield. 2004. Consumer choices of pork chops: Results from three consumer panels in France. Food Qual. Preference. 15:349-359.

Ockerman, H. W., and V. R. Cahill. 1977. Microbiological growth and pH effects on bovine tissue inoculated with Pseudomonas putrefaciens, Bacillus subtilis or Leuconostoc mesenteroides. J. Food Sci. 42:141-145.

Offer, G., and P. Knight. 1991. The structural basis of water-holding in meat part 2: drip losses. Pages 173-243 in Development in meat science. R. Lawrie, ed. Elsevier Applied Science, London, England.

Offer, G., and J. Trinick. 1983. On the mechanism of water-holding in meat: the swelling and shrinking of myofibrils. Meat Sci. 8:245-281.

Penny, I. F., C. A. Voyle, and R. A. Lawrie. 1963. The comparison of freeze-dried beef muscle of high and low ultimate pH. J. Sci. Food Agric. 14:53.

Roserio, L. C., C. Santos, and R. S. Melo. 1994. Muscle pH60, color, (L, a, b) and Water-holding capacity and the influence of postmortem meat temperature. Meat Sci. 38:353-359. 
Swatland, H. J. 1982a. Evaluation of pH-related aspects of pork quality by capacitance measurements in an abattoir. Can. J. Anim. Sci. 62:725-730.

Swatland, H. J. 1982b. Meat color of pork chops in relation to $\mathrm{pH}$ and adductor capacitance of intact carcasses. J. Anim. Sci. 54:264-267.

Swatland, H. J. 1989. Objective measurements of physical aspects of meat quality. Pages 64-73 in Proc. 42nd Recip. Meat Conf., Am. Meat Sci. Assoc., Guelph, Canada.

van Heugten, E. 2001. Understanding Pork Quality. Vol. 24, No. 3, North Carolina State Univ. Swine News, Raleigh, NC.

van Laack, R. L. J. M., R. G. Kauffman, W. Sybesma, F. J. M. Smulders, G. Eikelenboom, and J. C. Pinheiro. 1994. Is color brightness (L-value) a reliable indicator of water-holding capacity in porcine muscle? Meat Sci. 38:193-201.

Van Oeckel, M. J., N. van Warrants, and C. V. Boucque. 1999. Measurement and prediction of pork colour. Meat Sci. 52:347-354.

Wismer-Pedersen, J. 1959. Quality of pork in relation to rate of $\mathrm{pH}$ change post-mortem. Adv. Food Res. 24:711-718.

Wulf, D. M., S. F. O'Connor, J. D. Tatum, and G. C. Smith. 1997. Using objective measures of muscle color to predict beef longissimus tenderness. J. Anim. Sci. 75:684-692.

Yu, L. P., and Y. B. Lee. 1986. Effects of Postmortem pH and Temperature on Bovine Muscle Structure and Meat Tenderness. J. Food Sci. 51:774-780.

Zhu, L. G., and M. S. Brewer. 1998. Metmyoglobin reducing capacity of fresh normal, PSE, and DFD pork during retail display. J. Food Sci. 63:390-393. 


\section{Appendix A - Publications}

C. Bean, J. L. Jacobson, and S. M. Ryan. 2007. China, People's Republic of, Poultry and Products, Chicken paw, wing and wing tip exports to China. USDA GAIN Report $\mathrm{CH} 7006$.

C. Bean, and S. M. Ryan. 2006. China, People's Republic of, Poultry and Products, China now permits Hong Kong importers as consignee on bill of lading and health certificates. USDA GAIN Report CH6092.

S. M. Ryan, M. C. Hunt, M. Seyfert, and R. A. Mancini. 2005. Myoglobin denaturation as an indicator of internal cooked ground beef color. Proc $51^{\text {st }}$ ICoMST, Baltimore.

S. M. Ryan, and Z. Jianping. 2006. China, People's Republic of, Agricultural Situation, Newsflash I.19. USDA GAIN Report CH6103.

S. M. Ryan, M. Seyfert, M. C. Hunt, J. P. Grobbel, D. E. Johnson, and R. A. Monderen. 2006. Effects of potassium lactate and display lighting on shelf-life of fresh-pork-sausage patties. Proc $52^{\text {nd }}$ ICoMST, Dublin.

S. M. Ryan, M. Seyfert, M. C. Hunt, and R. A. Mancini. 2006. Influence of cooking rate, endpoint temperature, post cook hold time, and myoglobin redox state on internal cooked color development of ground beef patties. J Food Sci 71(3): C216-C221.

S. M. Ryan, J. A. Unruh, J. S. Drouillard, M. Seyfert, and M. E. Corrigan. 2006. Effects of concentrate level on carcass traits of boer crossbred goats. Small Rumin. Res. 73(1-3): $67-76$.

M. Seyfert, M. C. Hunt, J. P. Grobbel, S. M. Ryan, D. E. Johnson, and R. A. Monderen. 2006. Potassium lactate and fresh-pork-sausage formulation effects on shelflife in lighted and unlighted display. J Food Sci. 71(7): C390-C394. 


\section{Appendix B - Pearson's correlation coefficients, total population n = 1465}

\begin{tabular}{|c|c|c|c|c|c|c|c|c|c|c|c|c|c|c|c|c|}
\hline & $\begin{array}{c}\text { HCW, } \\
\text { kg }\end{array}$ & $\begin{array}{c}\text { Backfat, } \\
\text { mm }\end{array}$ & $\begin{array}{c}\text { Loin } \\
\text { depth, } \\
\text { mm }\end{array}$ & $\begin{array}{l}\text { Percent } \\
\text { lean, \% }\end{array}$ & $\begin{array}{c}\text { Ham } \\
\text { wt., kg }\end{array}$ & $\begin{array}{c}\text { Loin } \\
\text { wt., kg }\end{array}$ & $\begin{array}{c}\text { Boneless } \\
\text { loin wt., } \\
\text { kg }\end{array}$ & Marbling & Firmness & $\begin{array}{c}\text { pH, } \\
\text { ultimate }\end{array}$ & $\begin{array}{c}\text { Drip } \\
\text { loss, } \\
\%\end{array}$ & $\mathbf{L}^{*}$ & $\mathbf{a}^{*}$ & $\mathbf{b}^{*}$ & $\begin{array}{l}\text { Hue } \\
\text { angle }\end{array}$ & Chroma \\
\hline JCS & 0.05 & 0.03 & -0.02 & -0.04 & 0.06 & 0.03 & 0.01 & 0.06 & 0.13 & 0.41 & -0.42 & -0.87 & 0.28 & -0.24 & -0.19 & 0.29 \\
\hline HCW, kg & 1.00 & 0.38 & 0.48 & -0.21 & 0.89 & 0.79 & 0.78 & -0.02 & 0.12 & -0.02 & -0.03 & -0.02 & 0.22 & 0.14 & 0.14 & 0.06 \\
\hline Backfat, mm & & 1.00 & 0.10 & -0.94 & 0.21 & 0.12 & 0.01 & 0.17 & 0.06 & 0.09 & -0.08 & 0.03 & 0.14 & 0.04 & 0.05 & 0.03 \\
\hline Loin depth, mm & & & 1.00 & 0.24 & 0.44 & 0.46 & 0.51 & -0.06 & 0.09 & -0.06 & 0.03 & 0.02 & 0.10 & 0.06 & 0.06 & 0.04 \\
\hline Percent lean, \% & & & & 1.00 & -0.06 & 0.04 & 0.16 & -0.19 & -0.03 & -0.11 & 0.09 & -0.02 & -0.11 & -0.02 & -0.03 & -0.01 \\
\hline Ham wt, kg & & & & & 1.00 & 0.70 & 0.76 & -0.05 & 0.09 & -0.09 & -0.01 & -0.05 & 0.12 & 0.12 & 0.12 & -0.28 \\
\hline Loin wt, kg & & & & & & 1.00 & 0.84 & -0.11 & 0.13 & -0.01 & -0.01 & 0.05 & 0.23 & -0.08 & -0.06 & -0.24 \\
\hline $\begin{array}{l}\text { Boneless loin wt, } \\
\text { kg }\end{array}$ & & & & & & & 1.00 & -0.12 & 0.08 & -0.10 & 0.03 & 0.00 & 0.12 & 0.08 & 0.07 & -0.06 \\
\hline Marbling & & & & & & & & 1.00 & 0.10 & 0.09 & -0.11 & -0.02 & 0.09 & 0.08 & 0.95 & 0.88 \\
\hline Firmness & & & & & & & & & 1.00 & 0.18 & -0.12 & -0.09 & 0.06 & -0.08 & -0.07 & -0.02 \\
\hline pH, ultimate & & & & & & & & & & 1.00 & -0.53 & -0.34 & 0.12 & -0.27 & -0.22 & 0.21 \\
\hline Drip loss, \% & & & & & & & & & & & 1.00 & 0.37 & 0.02 & 0.16 & 0.11 & 0.00 \\
\hline $\mathbf{L}^{*}$ & & & & & & & & & & & & 1.00 & -0.09 & -0.02 & -0.02 & -0.35 \\
\hline $\mathbf{a}^{*}$ & & & & & & & & & & & & & 1.00 & -0.02 & 0.00 & 0.39 \\
\hline $\mathbf{b}^{*}$ & & & & & & & & & & & & & & 1.00 & 0.95 & 0.28 \\
\hline Hue angle & & & & & & & & & & & & & & & 1.00 & 0.23 \\
\hline Chroma & & & & & & & & & & & & & & & & 1.00 \\
\hline
\end{tabular}

